\title{
O impacto de elementos de realidade virtual em usuários de interfaces gráficas tridimensionais
}

Gilberto da Silva Hemerly

\author{
DISSERTAÇÃO APRESENTADA \\ $\mathrm{AO}$ \\ INSTITUTO DE MATEMÁTICA E ESTATÍSTICA \\ DA \\ UNIVERSIDADE DE SÃO PAULO \\ PARA \\ OBTENÇÃO DO TÍTULO DE MESTRE \\ EM \\ CIÊNCIA DA COMPUTAÇÃO
}

Área de Concentração: Ciência da Computação - Computação Gráfica

Orientador: Prof. Dr. Antonio Elias Fabris 


\section{Resumo}

Neste trabalho fazemos um levantamento de interfaces gráficas tridimensionais em uso atualmente, tanto no campo prático como no campo da pesquisa. Investigamos os paradigmas atualmente em uso no campo de interação humano-computador e analisamos como eles são utilizados no projeto de interfaces gráficas.

Mostramos como certos elementos de realidade virtual podem ter influência em usuários que utilizam este tipo de interface, influenciando tanto sua eficiência como sua percepção subjetiva do sistema. 


\begin{abstract}
In this work, we conduct a survey of three-dimensional graphical interfaces, both in current practical use and in the research field. We investigate the paradigms currently in use in the field of human-computer interaction and analyze how they are applied to the design of graphical interfaces.
\end{abstract}

We show how certain virtual reality elements can influence the users of these types of interfaces, affecting both their efficiency as well as their subjective perception of the system. 


\section{Índice}

1 Introdução................................................................................................................ 1

2 Definições Básicas................................................................................................ 3

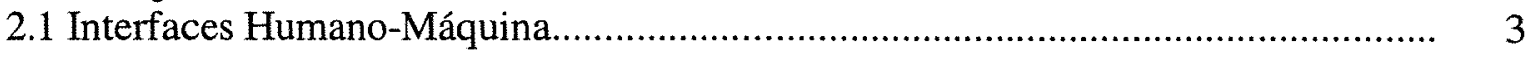

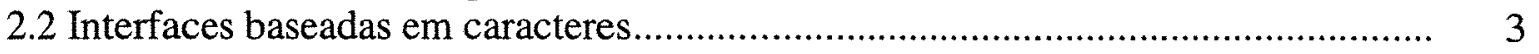

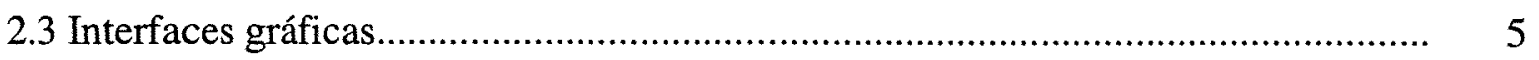

2.3.1 Elementos de uma interface gráfica....................................................... 6

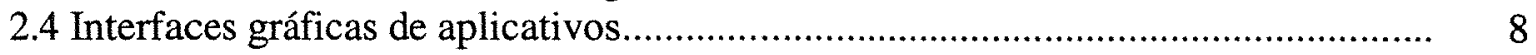

3 Computação Gráfica em Três Dimensões............................................................. 10

3.1 Percepção de distância e profundidade............................................................ 11

3.1.1 Referências monoculares...................................................................... $\quad 11$

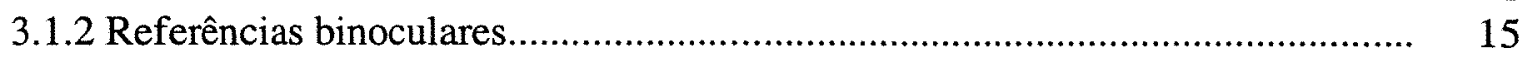

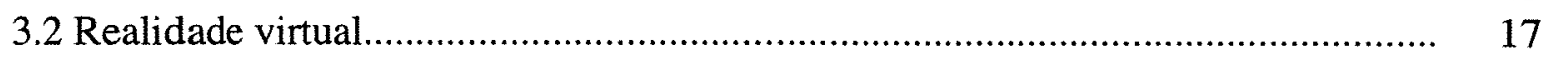

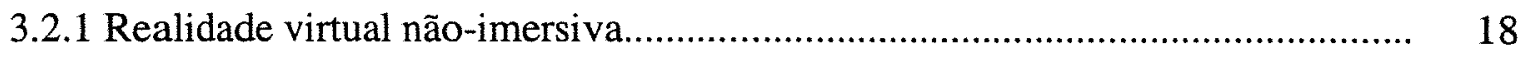

4 Aspectos Cognitivos em Interfaces de Usuário.................................................... 21

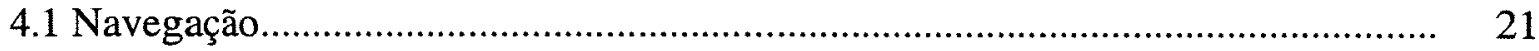

4.1.1 Mapas Cognitivos................................................................................. 22

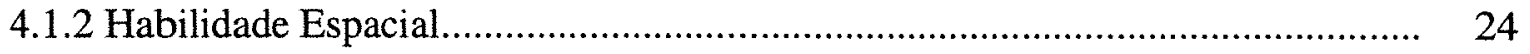

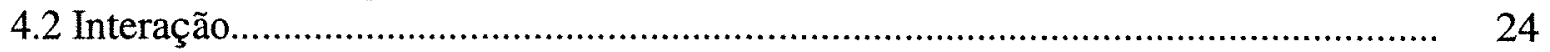

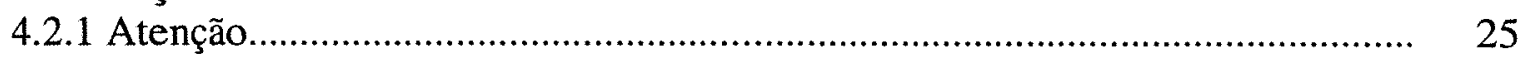

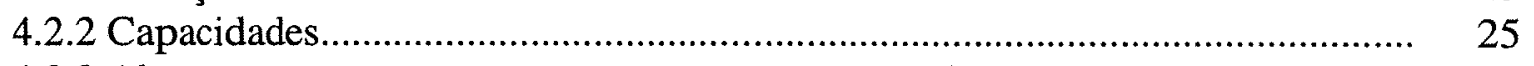

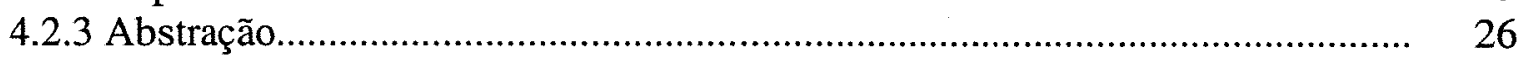

5 Áreas de Aplicação de Interfaces Tridimensionais.................................................. 28

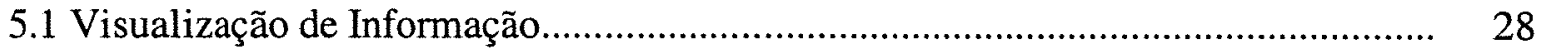

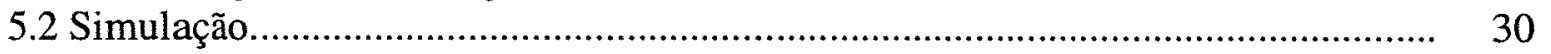

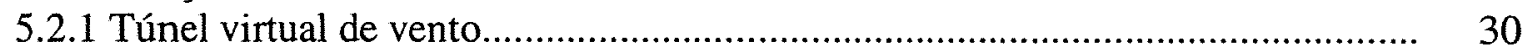

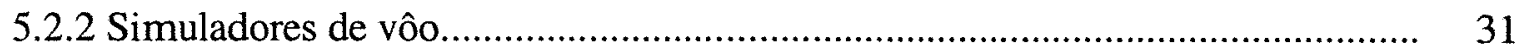

5.2.3 CAD (Computer Aided Design) .............................................................. 32

5.2.4 Trabalho cooperativo através do computador............................................... 33

5.3 Substitutos para o gerenciador de arquivos................................................ 35

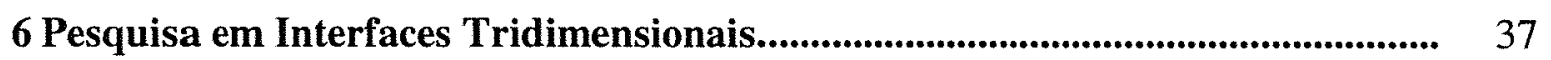

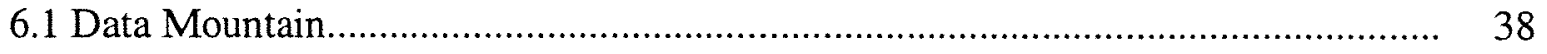

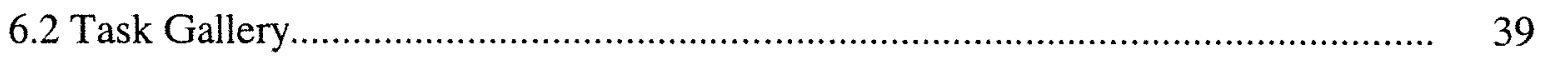

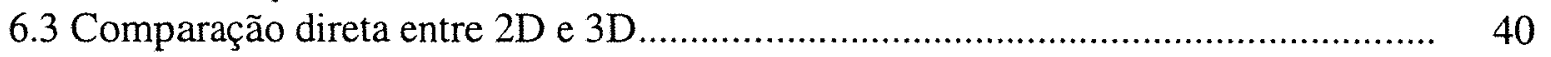

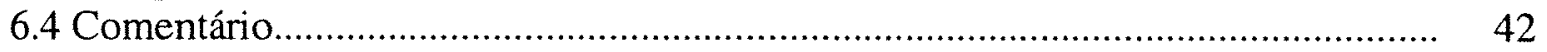


7 Considerações de Projeto para Interfaces 3D....................................................... 43

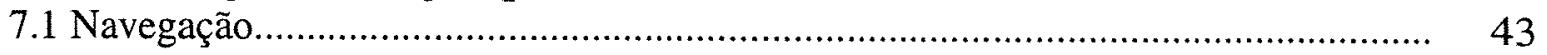

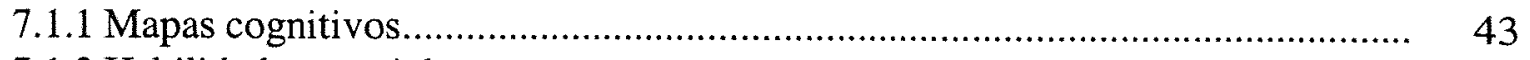

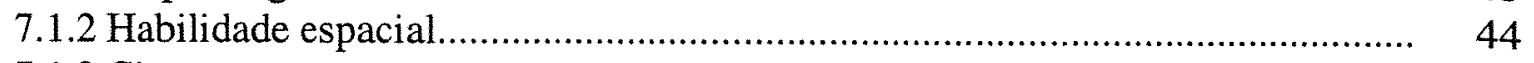

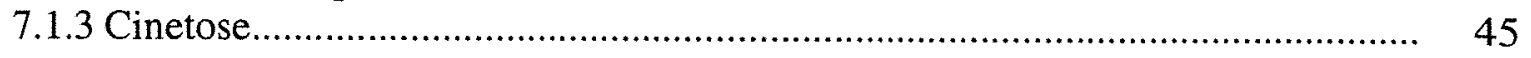

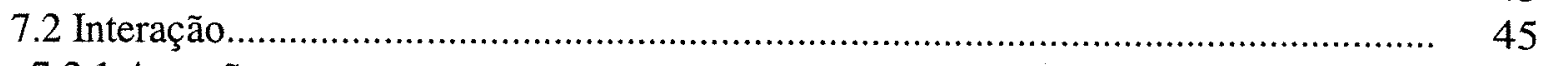

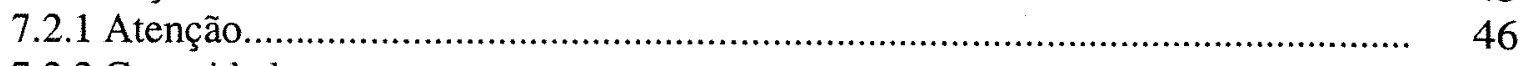

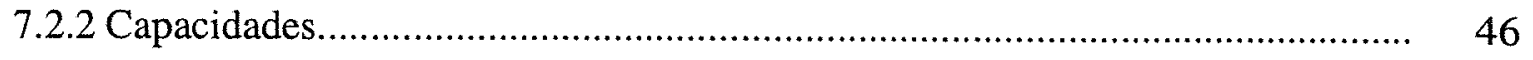

8 Influência de Elementos de Realidade Virtual........................................................ 48

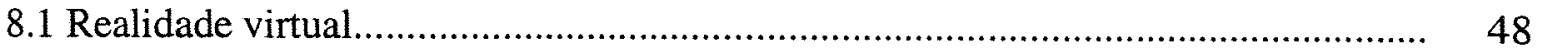

8.2 Protótipo de uma interface tridimensional.................................................... 50

8.2.1 Alguns aspectos cognitivos.................................................................. 53

8.2.2 Implementação...................................................................................... 54

8.2.3 Movimento no ambiente virtual.............................................................. 55

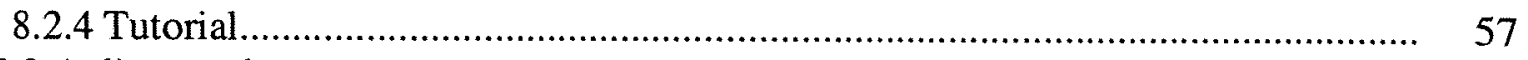

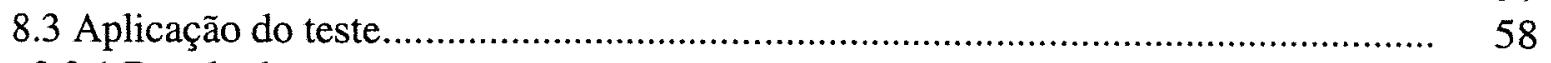

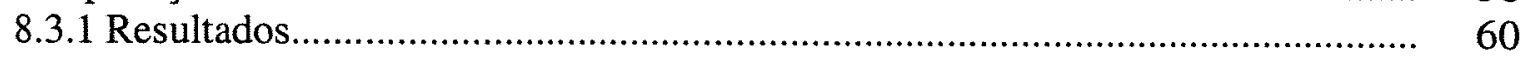

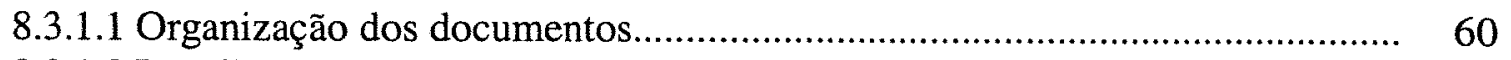

8.3.1.2 Localização dos documentos..................................................................... 62

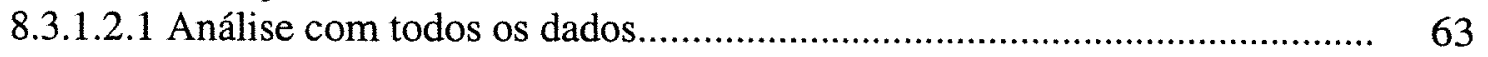

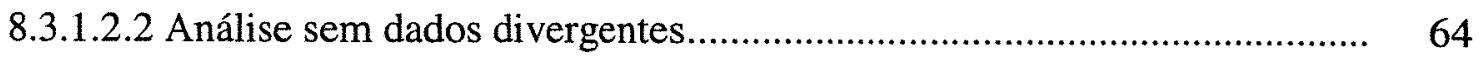

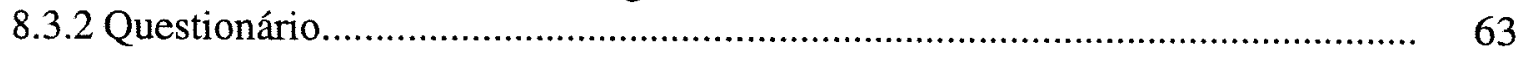

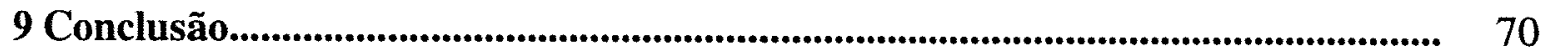




\section{Lista de Figuras}

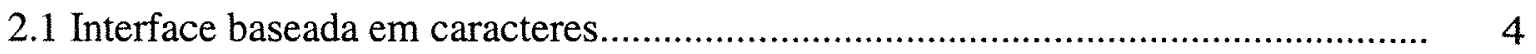

2.2 Interface gráfica baseada em texto............................................................... 5

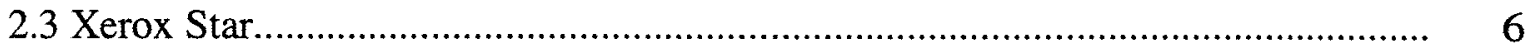

2.4 Execução do gerenciador de janelas........................................................................ 7

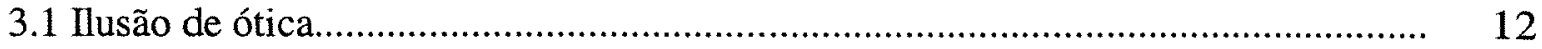

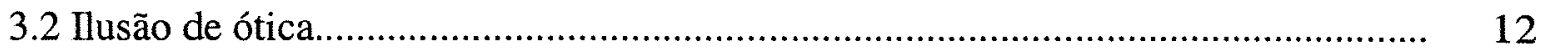

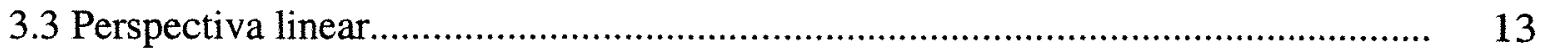

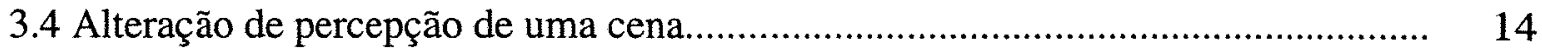

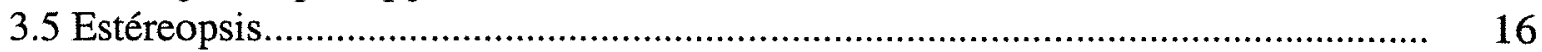

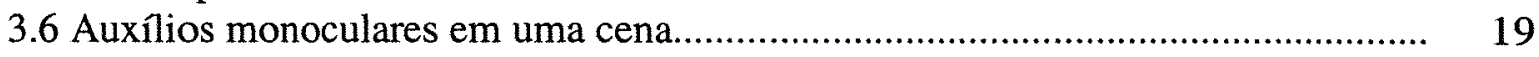

3.7 Equipamentos para movimentação em três dimensões.................................... 20

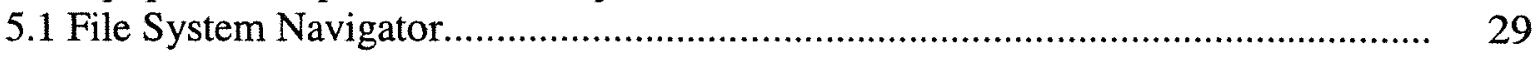

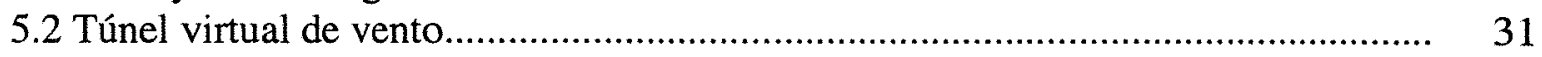

5.3 Ambiente Interativo Virtual Distribuído....................................................... 34

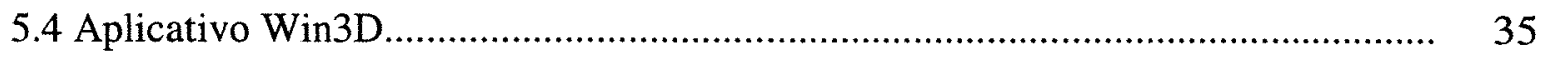

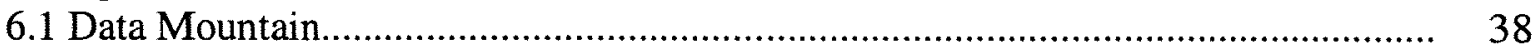

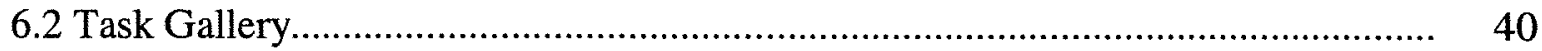

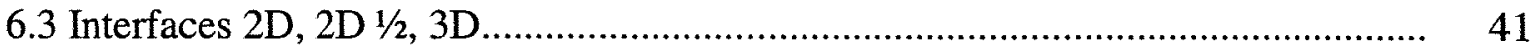

8.1 Interface tridimensional - parte realista ........................................................ 49

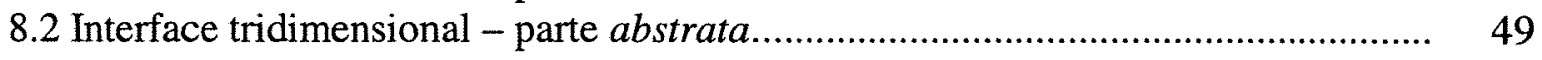

8.3 Ponto de vista inicial.................................................................................... 52

8.4 Ponto de vista após rotação para a esquerda.................................................... 52

8.5 Exemplos de texturas utilizadas nos documentos............................................. 54

8.6 Sistema de movimentação........................................................................... 55

8.7 Gráfico das diferenças entre as distribuições de tempos........................................ 62 


\section{Lista de tabelas}

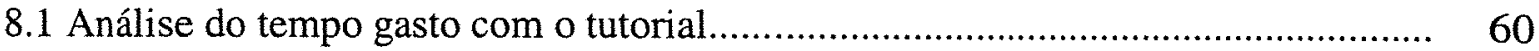

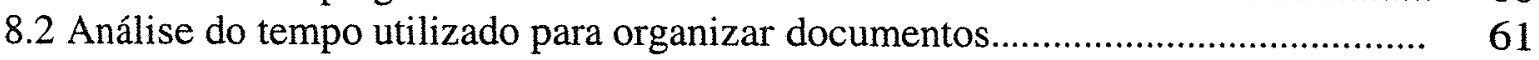

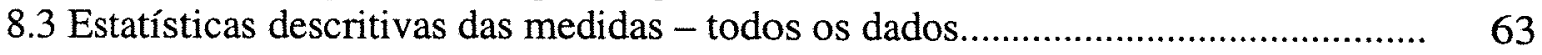

8.4 Estatísticas descritivas das medidas - sem dados divergentes.............................. 64

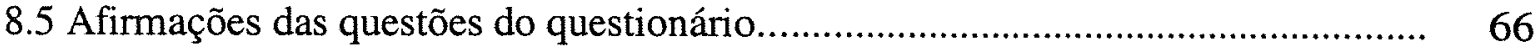

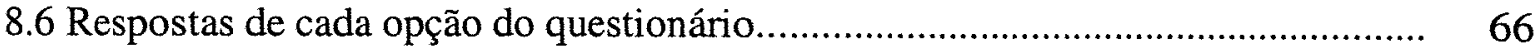




\section{Capítulo 1}

\section{Introdução}

Este trabalho tem dois objetivos principais: fazer um levantamento de interfaces gráficas tridimensionais em uso atualmente, tanto no campo prático como no campo da pesquisa, e analisar o impacto que certos elementos de realidade virtual podem ter no uso deste tipo de interface.

Iremos investigar os paradigmas atualmente em uso no campo de interação humanocomputador e analisar como eles são utilizados no projeto de interfaces gráficas. Iremos também investigar as diferenças entre interfaces bidimensionais e tridimensionais, e como cada tipo é utilizado atualmente.

Para analisar o impacto de elementos de realidade virtual em interfaces gráficas tridimensionais, implementaremos um protótipo que nos permitirá observar o impacto destes elementos durante o uso da interface por uma série de usuários.

No segundo capítulo, introduziremos os conceitos básicos sobre interfaces e faremos um breve resumo dos paradigmas em uso em interfaces gráficas bidimensionais.

No terceiro capítulo, mostraremos conceitos de computação gráfica em três dimensões e quais as técnicas geralmente utilizadas para a criação de gráficos e interfaces tridimensionais.

No quarto capítulo, falaremos sobre aspectos cognitivos em interfaces e como estes podem influenciar o uso destas interfaces. 
O quinto capítulo mostra onde as interfaces gráficas tridimensionais estão sendo usadas atualmente e o sexto capítulo mostra algumas pesquisas recentes feitas neste campo.

O sétimo capítulo apresenta algumas considerações a serem feitas durante o projeto de interfaces gráficas, sejam elas bidimensionais ou tridimensionais.

O oitavo capítulo mostra a implementação do nosso protótipo de interface tridimensional e analisa o resultado obtido durante os testes com os usuários. 


\section{Capítulo 2}

\section{Definições Básicas}

Nesta seção, procuraremos dar algumas definições básicas sobre interfaces, a fim de estabelecer os conceitos utilizados.

\subsection{Interfaces Homem-Máquina}

Ainda não existe atualmente uma definição globalmente aceita do conjunto de áreas que formam o campo de interação homem-computador (ou HCI, do inglês Human-Computer Interaction). É possível, porém, definir este campo da Ciência da Computação como sendo uma disciplina preocupada com o projeto, análise e implementação de sistemas interativos para uso do homem, e o estudo dos fenômenos que os cercam [Hewett01a]. É uma definição ampla, que permite várias interpretações dependendo da definição aplicada a sistemas interativos, que podem ser desde fornos de microondas até painéis de naves espaciais No nosso contexto, consideraremos tais sistemas como sendo um único computador utilizado por um único usuário.

\subsection{Interfaces baseadas em caracteres}

Uma interface baseada em caracteres é geralmente representada como uma matriz de pequenos quadrados, e cada um destes quadrados pode conter um caractere. Como este tipo de interface somente pode exibir textos, os usuários precisam interagir com o sistema digitando comandos em um teclado. A figura 2.1 mostra um exemplo.

O dispositivo básico de entrada na maioria dos computadores pessoais é o teclado. Conforme caracteres são digitados, eles são guardados na memória e copiados para um 
sistema básico de saída, que neste caso é o monitor. Interfaces baseadas em caracteres podem ser simples, mas são muitas vezes difíceis de serem aprendidas por um usuário novato, devido ao fato de que a sintaxe dos comandos deve ser lembrada antes de ser digitada, e muitas vezes esta sintaxe pode ser complexa. Porém, uma vez aprendida, tais interfaces podem ser poderosas e flexíveis, especialmente nas mãos de usuários avançados. Mesmo assim, o número de erros cometidos durante o uso tende a ser alto, treinamento é necessário para se usar a interface com eficiência, a sintaxe dos comandos pode ser esquecida, e as mensagens de erro podem ser difíceis de se entender [Pre94a].

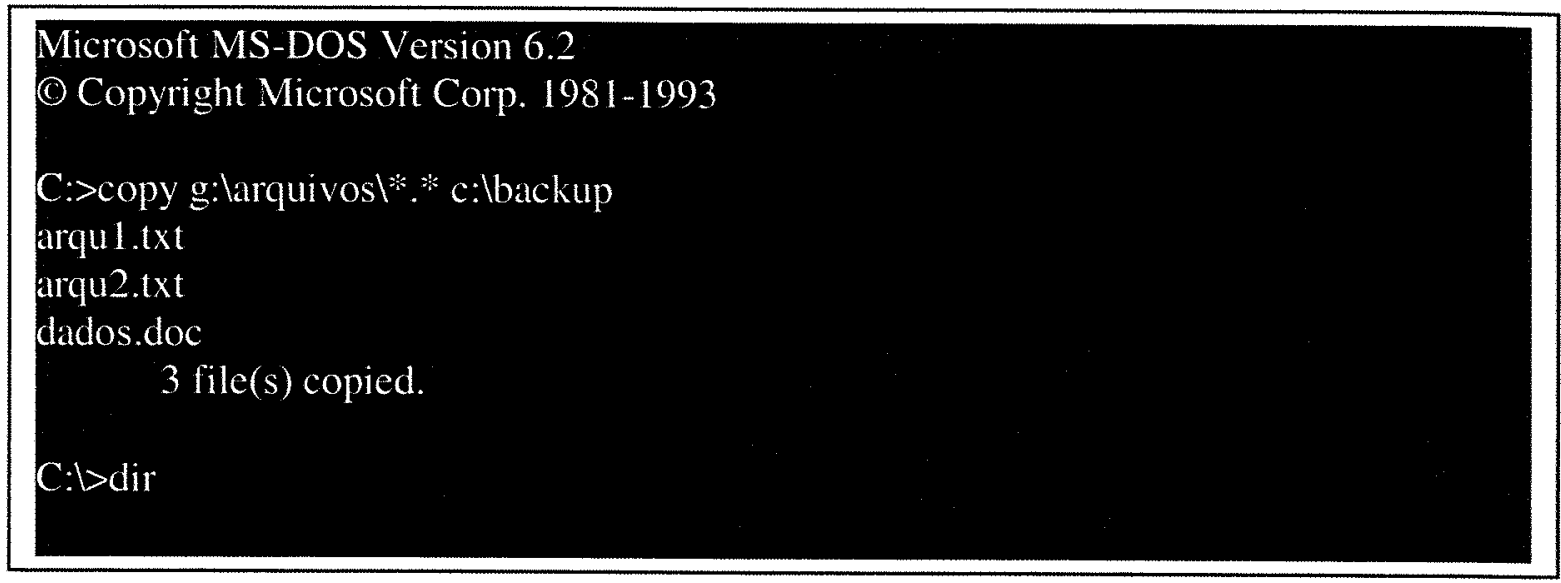

Figura 2.1 - Interface baseada em caracteres

Algumas interfaces baseadas em caracteres incluem algumas características de interfaces gráficas, como um menu, por exemplo. Outras ainda incluem alguns artifícios para desenhar simples objetos, porém não são capazes de representar objetos mais complicados, como curvas. São algumas vezes chamadas de interfaces gráficas baseadas em caracteres, para distingui-las das interfaces que são totalmente gráficas [Pre94a]. Este tipo de interface foi amplamente utilizado durante o início da década de noventa. Algumas destas interfaces chegaram a tal ponto de conseguir exibir elementos gráficos complexos em uma tela de caracteres. A figura 2.2 mostra um exemplo de uma interface gráfica baseada em texto. 


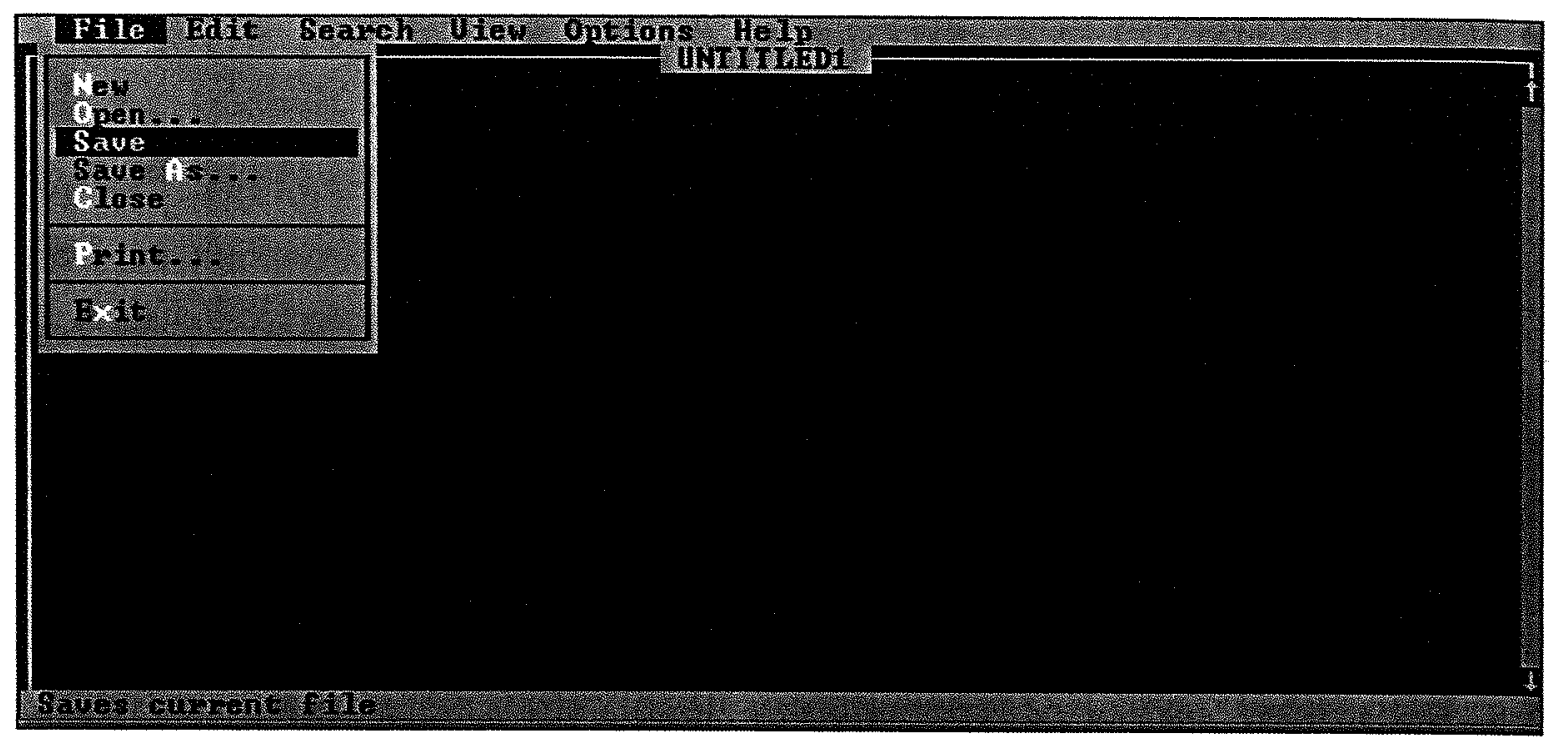

Figura 2.2 - Interface gráfica baseada em texto

\subsection{Interfaces Gráficas}

Uma interface gráfica (ou GUI, do inglês graphical user interface) é um tipo de interface que permite a interação entre um usuário e o computador [Jansen98a, Foley92a], e como tal são consideradas elementos importantes na área de interfaces homem-máquina. Foram desenvolvidas com o intuito de resolver as dificuldades encontradas pelos usuários com as interfaces que utilizavam somente texto; quando se deparavam com uma tela vazia, com somente um prompt, muitos ficavam sem saber o que fazer. O computador não auxiliava o usuário indicando o que poderia ser feito.

A primeira interface gráfica a utilizar a metáfora do ambiente de trabalho (desktop), foi a Xerox Star, criada em 1977, e mostrada na figura 2.3. Porém, esta metáfora foi popularizada de fato pelos sistemas da Apple e Microsoft. 


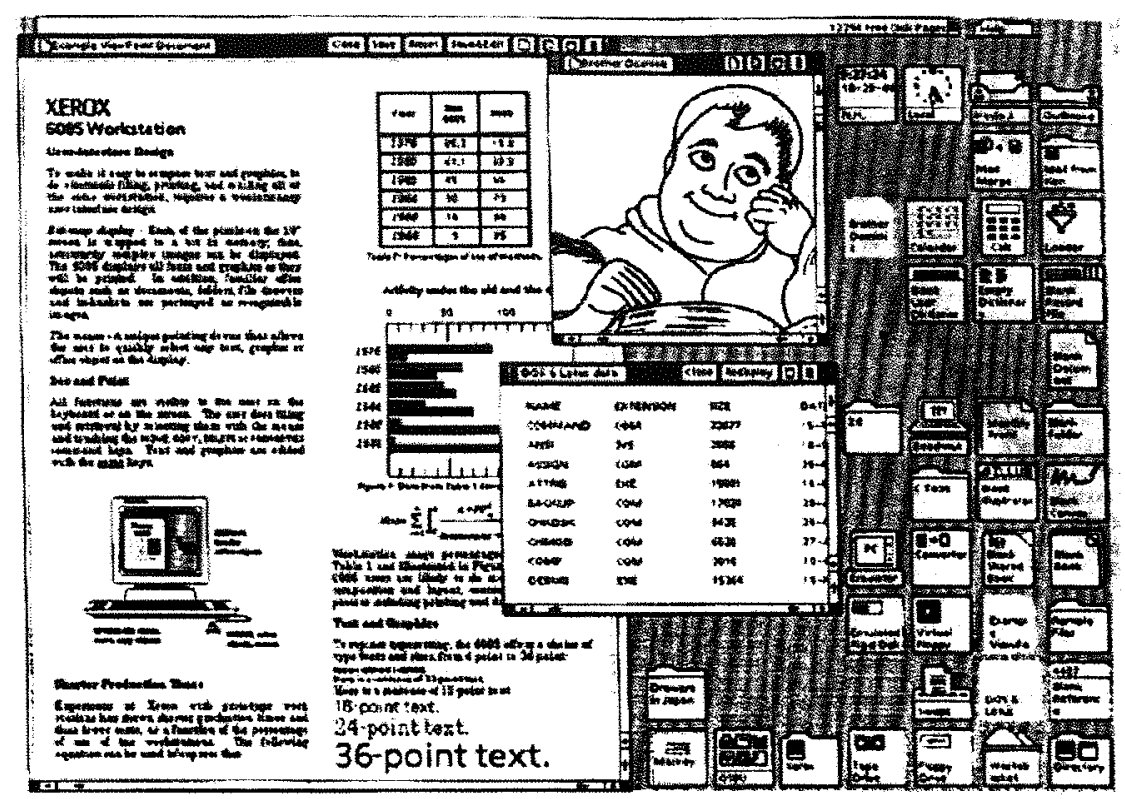

Figura 2.3 - Xerox Star

De uma certa forma, é a interface gráfica a grande responsável por criar o elo de ligação entre o usuário e o sistema operacional da máquina. Uma interface deve tornar todo o potencial do sistema operacional facilmente disponível para o usuário. Um bom projeto de interface remove possíveis dificuldades de comunicação entre a máquina e o usuário, e permite que este concentre-se em utilizar os aplicativos [Jansen98a].

\subsubsection{Elementos de uma interface gráfica}

Interfaces gráficas possuem três elementos principais: o sistema de janelas, um modelo de imagens e uma interface de programa (mais conhecido como API, Application Program Interface). O sistema de janelas, como o próprio nome indica, controla o uso de recursos como janelas e ícones. $O$ modelo de imagem define letras e gráficos e serem exibidos na tela, e a interface de programa permite que um usuário especifique como a interface gráfica deve ser exibida [Fol92a]. 
Destes elementos, o mais importante é o sistema de janelas, que disponibiliza muitas características de interfaces gráficas modernas: exibição de vários aplicativos na tela ao mesmo tempo, habilidade de poder redefinir a área nas quais estes aplicativos são exibidos, menus pop-up e caixas de diálogo [Foley92a]. Assim como o sistema operacional é um gerente de recursos, podemos dizer que o sistema de janelas também o é, diferindo apenas no tipo de recurso gerenciado. Como o sistema de janelas permite que o usuário trabalhe em vários aplicativos ao mesmo tempo, ele é responsável por alocar os recursos dos dispositivos de entrada, e então enviar a informação destes dispositivos ao aplicativo adequado.

Um sistema de janelas possui duas partes importantes: o gerenciador de janelas, e o sistema de janelas em si. O gerenciador de janelas é a parte com a qual o usuário interage diretamente, recebendo requisições para manipular as janelas na tela do computador. A segunda parte, o sistema de janelas, é a parte do sistema que recebe o resultado das manipulações do usuário e as implementa na prática.

O gerenciador de janelas pode ser visto como uma camada da interface gráfica que fica sob o sistema de janelas. Deste modo, o gerenciador de janelas utiliza serviços disponibilizados pelo sistema de janelas. Os aplicativos e bibliotecas, por sua vez, formam a camada mais alta, e utilizam-se dos serviços do gerenciador de janelas. A figura 2.4 ilustra este fato.

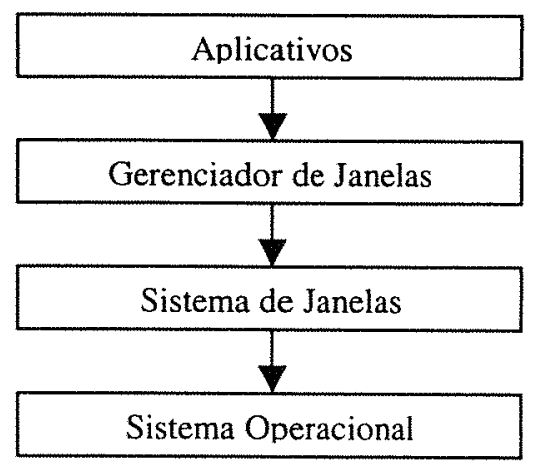

Figura 2.4 - Execução do gerenciador de janelas 
Como exemplo, podemos citar o exemplo do sistema X-Windows: o gerenciador de janelas utilizado muitas vezes não é o próprio X-Windows, mas outro como KDE ou Gnome. Estes últimos são os responsáveis pela aparência das janelas e ícones na tela, além de fornecer algumas facilidades adicionais, como recursos de "copiar e colar", por exemplo. Porém, o controle interno das janelas e dos recursos é feito pelo X-Windows, que fornece esses serviços para o gerenciador de janelas, tipicamente através de uma interface de programa (API).

Em outros casos, o sistema de janelas confunde-se com o gerenciador de janelas e até mesmo o sistema operacional, apesar de serem elementos distintos. Por exemplo, em sistemas Microsoft Windows, muitos consideram a aparência gráfica da interface como sendo imutável, o que não é verdade. O gerenciador de janelas, chamado de Explorer, é nada mais que um processo que controla a aparência de ícones e menus na tela. Nestes sistemas Windows é possível, inclusive, fechar o processo do gerenciador de janelas e comunicar-se diretamente com o sistema de janelas, sem que seja necessário o uso de interfaces de programa. Porém, perde-se muito em funcionalidade.

\subsection{Interfaces Gráficas de Aplicativos}

Assim como o sistema operacional, aplicativos podem também ter sua própria interface, geralmente exibida dentro de sua própria janela. Podemos dividir as interfaces gráficas dos aplicativos atuais em dois grupos básicos: WIMP e Web [Ivory01a]. Interfaces Web são na maioria das vezes utilizadas em conjunto com interfaces WIMP, porém a distinção se faz necessária uma vez que métodos formais de análise aplicados em um tipo de interface podem não ser úteis para outro tipo. Interfaces WIMP costumam ter muito mais funcionalidade que interfaces Web. 
Em interfaces WIMP, usuários realizam tarefas, como por exemplo abrir e gravar arquivos, através de seqüências específicas de operação. Caracterizam-se pela presença de janelas, ícones, menus e um ponteiro, geralmente controlado pelo mouse. Daí vem seu nome WIMP (do inglês windows, icons, pointer, menus). Interfaces Web são utilizadas, na sua maioria, na World Wide Web. Caracterizam-se por permitir que o usuário realize tarefas selecionando atalhos em um documento de hipertexto. Apesar de existirem outros meios de comunicação com o usuário, como por exemplo campos de texto e botões, interfaces Web têm a sua funcionalidade muito limitada [Ivory01a]. 


\section{Capítulo 3}

\section{Computação Gráfica em Três Dimensões}

$\mathrm{Na}$ literatura o termo "interface gráfica 3D” é usado para descrever uma grande variedade de interfaces que permitem exibição e/ou interação com objetos em três dimensões. Interfaces verdadeiramente tridimensionais, isto é, interfaces nas quais todos os seus componentes são tridimensionais, ainda são raras e geralmente vistas apenas em laboratórios de pesquisa. As interfaces atuais consideradas tridimensionais são na sua maioria híbridos, com elementos em duas e três dimensões. Neste texto, consideraremos estas interfaces híbridas simplesmente como interfaces tridimensionais.

Inicialmente, a computação gráfica em três dimensões era de uso exclusivo de alguns grupos de cientistas e engenheiros que tinham acesso a super computadores. Hoje em dia, o aumento do poder de processamento dos computadores pessoais, assim como o aparecimento e aprimoramento de aceleradores gráficos, permitem que gráficos em três dimensões sejam usados em uma grande quantidade de computadores, o que por sua vez aumentou o interesse em incluir três dimensões nas interfaces gráficas [Mullet95a]. Atualmente, o uso de gráficos em três dimensões em interfaces é comum nas áreas de $\mathrm{CAD} / \mathrm{CAM}$, medicina, engenharia e até mesmo na indústria de entretenimento. Como os objetivos de cada grupo podem diferir radicalmente entre si, não existe ainda um consenso sobre algum padrão que deva ser adotado durante o projeto de interfaces gráficas tridimensionais. Uma das possíveis soluções sendo pesquisadas atualmente seria utilizar os recursos que gráficos em três dimensões oferecerem para permitir que os usuários destas interfaces utilizem, para navegação no sistema, as mesmas habilidades que usam para navegar no mundo real. Uma destas tentativas inclui o uso de realidade virtual, que é um campo muito utilizado quando se trata de interfaces gráficas tridimensionais. 


\subsection{Percepção de distância e profundidade}

Um tópico importante no campo de gráficos tridimensionais é como exibir objetos de modo que os usuários consigam efetivamente localizar suas posições relativas. Para que isto seja feito, é importante considerar como a profundidade de objetos é percebida pelos seres humanos.

Por exemplo, como uma pessoa consegue distinguir, a partir de uma imagem bidimensional, onde os objetos estão localizados no espaço? Em uma situação normal, o cérebro humano consegue obter esta informação através da imagem que chega na retina. A retina recebe a imagem em duas dimensões, e o cérebro, através da análise de uma série de elementos, transforma essa imagem em três dimensões. Isto é feito através do uso de referências monoculares (que requerem apenas um olho) e referências binoculares (que requerem ambos os olhos) [Smith93a].

\subsubsection{Referências monoculares}

Referências monoculares são relevantes em computação gráfica uma vez que são essas referências que serão usadas para criar a ilusão de profundidade em um monitor bidimensional. Esses efeitos de profundidade criados são eficientes tanto quando usamos um olho ou os dois olhos para visualizar o monitor.

Com o uso eficiente de referências monoculares é possível criar imagens cujas partes individuais sejam coerentes mas cuja organização geral não faça sentido quando visualizamos a imagem como um todo. Isto pode ser exemplificado através de figuras comumente categorizadas como "ilusões de ótica", conforme mostram as figuras 3.1 e 3.2. 


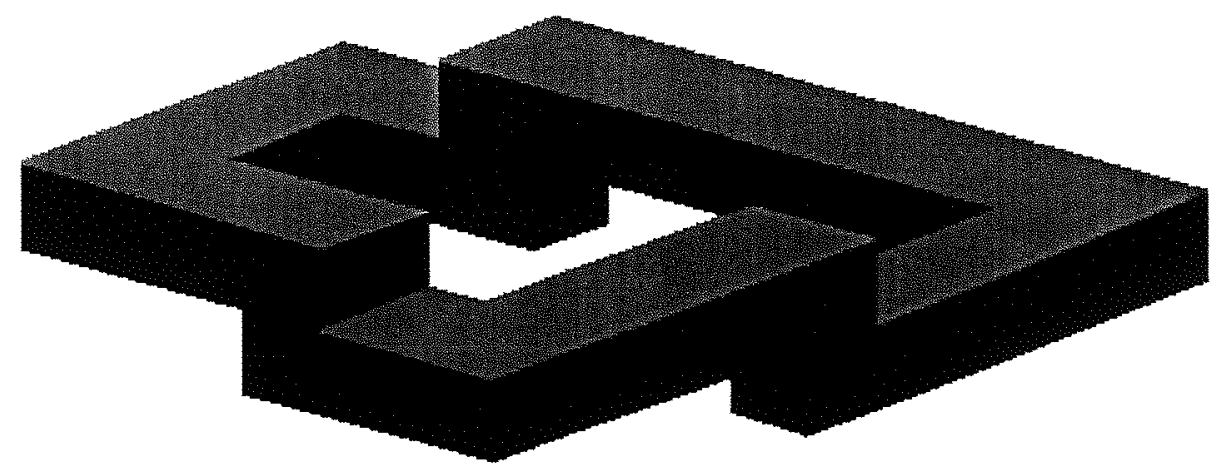

Figura 3.1 - Ilusão de ótica

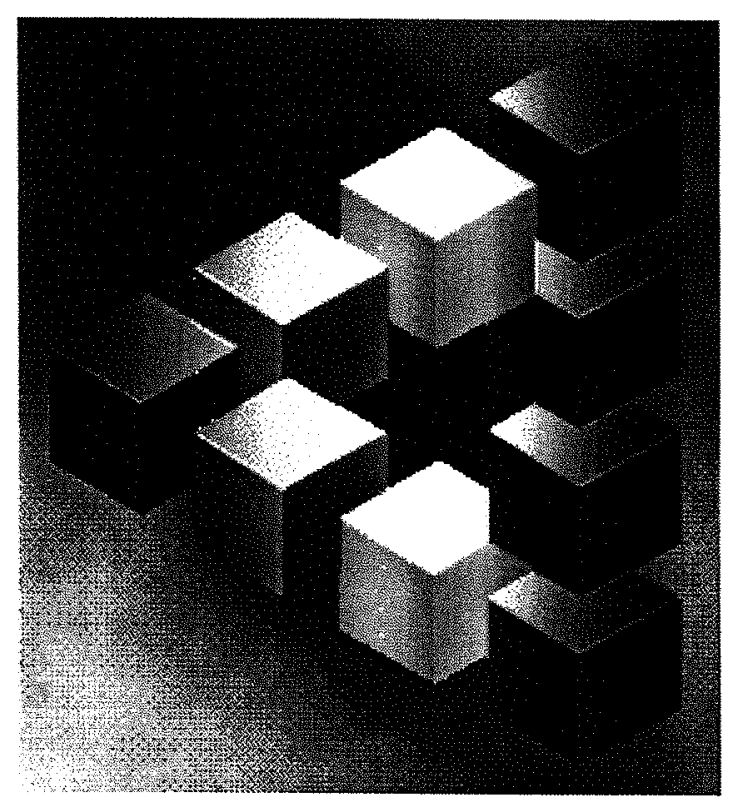

Figura 3.2 - Ilusão de ótica

Outra referência monocular importante é chamada de perspectiva linear. Para exemplificar esta referência, imagine-se em cima de um trilho de trem reto, que desaparece no horizonte. Conforme distanciam-se de nós, os trilhos parecem aproximar-se um dos outros. A figura 3.3 ilustra este fato. 


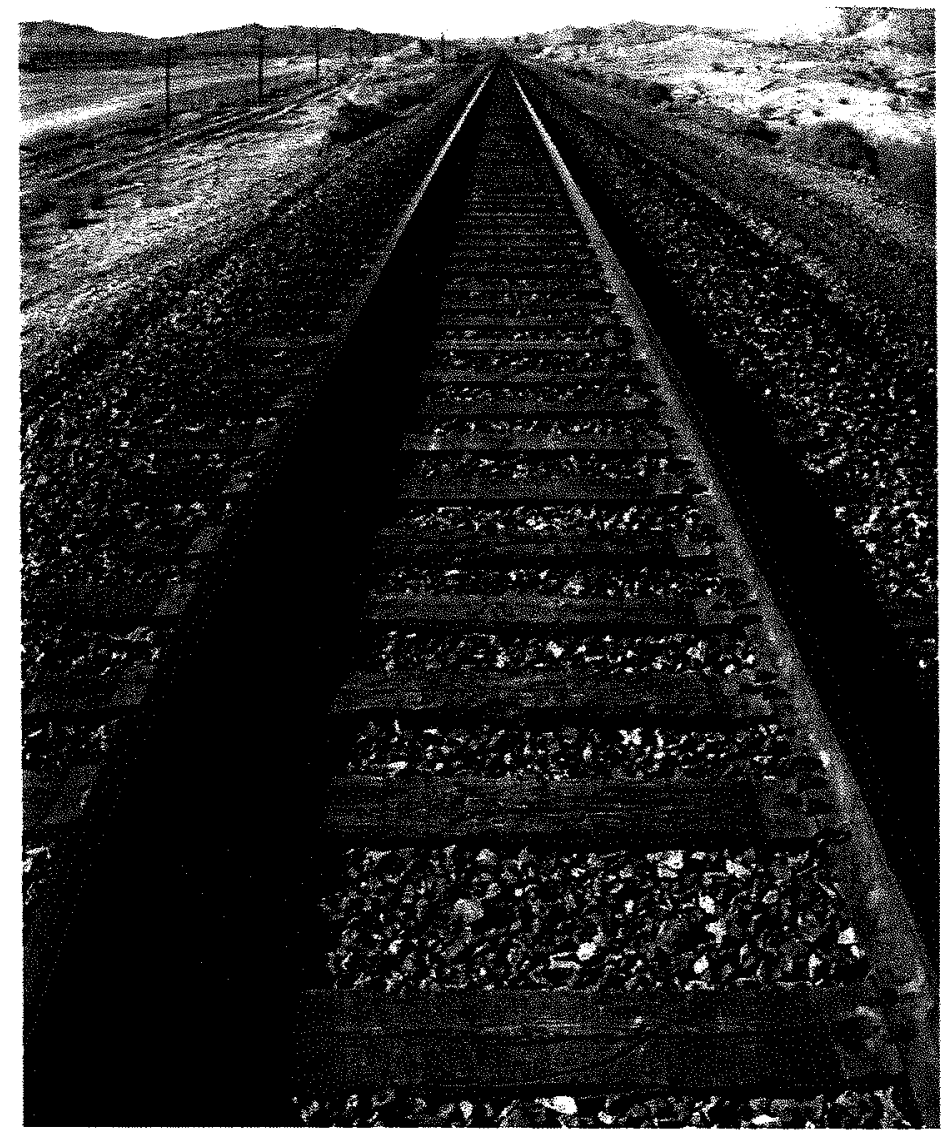

Figura 3-3

Outras referências monoculares incluem, por exemplo, objetos diminuindo de tamanho. Neste caso, objetos que estão mais longe de nós parecem menores do que objetos que estão mais perto. Além disso, objetos que estão mais longe parecem estar em um plano acima de objetos que estão mais perto. Textura e clareza dos objetos também afetam o modo como percebemos profundidade; nós podemos ver mais claramente e com mais detalhes objetos que estão mais perto de nós.

Iluminação e sombras também auxiliam na percepção de profundidade, e talvez sejam as referências que mais ajudam na ilusão de três dimensões. A presença de umas poucas sombras pode alterar radicalmente a nossa percepção de uma cena. A figura 3.4 é um 
exemplo disto. $\mathrm{Na}$ imagem à esquerda, os dois cilindros parecem estar igualmente distantes um do outro, exceto pelo fato de um estar posicionado em um plano mais alto. Quando as sombras são removidas, como pode ser visto na imagem à direita, a nossa percepção do posicionamento dos cilindros muda completamente: agora os dois cilindros parecem estar na mesma altura, porém um está mais longe do que o outro.

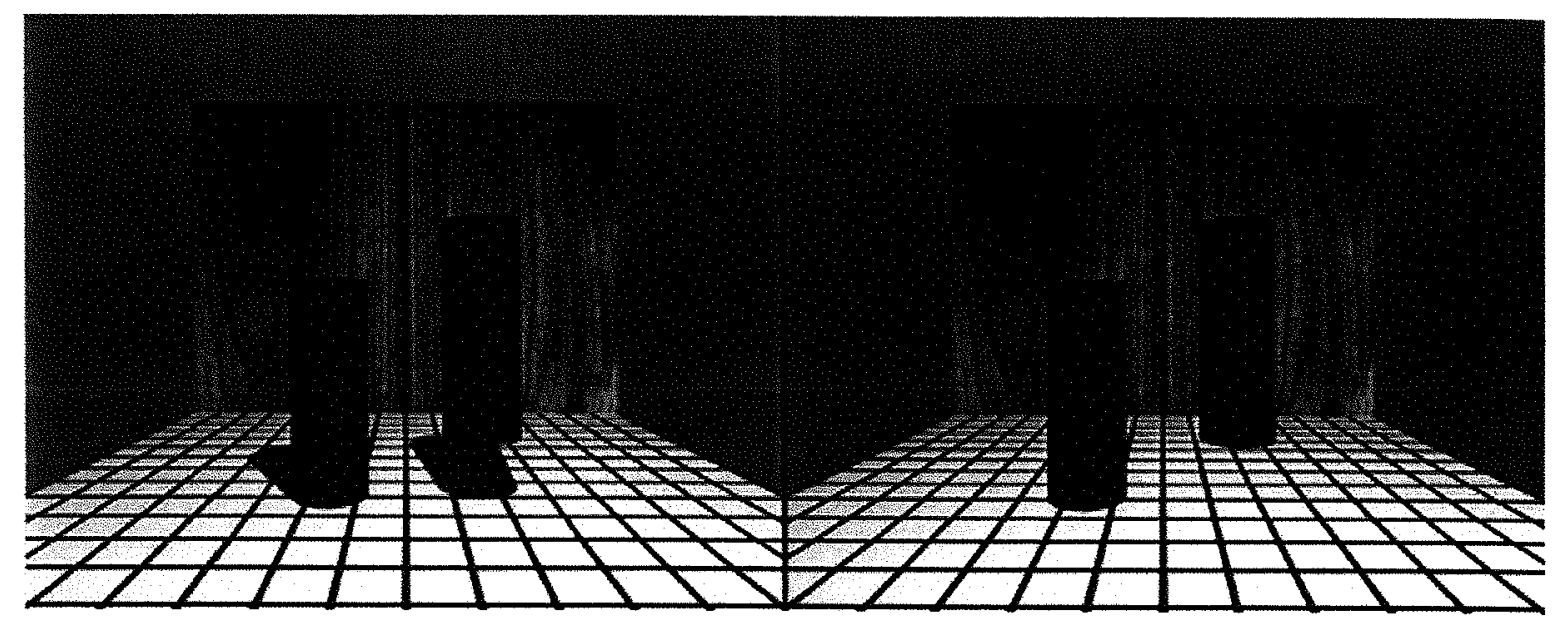

Figura 3.4 - Alteração de percepção de uma cena

Perspectiva linear, iluminação, sombras e texturas são referências importantes na criação de uma cena tridimensional. Porém, nem todos os computadores têm o poder de processamento necessário para calcular em tempo real todos estes efeitos. Sem algumas destas referências, ilusões como aquelas mostradas na figura 3.4 podem alterar completamente o sentido de uma cena. O problema se agrava quando considerarmos que, nestes casos, a cena continua sendo "válida" para nós, ou seja, não há erro aparente. Sendo assim, a omissão de uma referência levou a uma interpretação válida, porém diferente daquela pretendida.

Por este motivo, é importante levar em consideração quais são as referências necessárias para que uma cena possa ser interpretada corretamente. É também interessante saber se a 
importância de uma referência varia de acordo com o objetivo para o qual a cena será utilizada. Wang e Ferwerda estudaram como estas referências influenciam uma cena, e como sua remoção afeta a percepção dos usuários, além de sua habilidade de realizar tarefas no ambiente tridimensional [Wan92a].

A pesquisa levou a duas conclusões importantes:

- Nem todas as referências são igualmente eficientes. Algumas referências, como texturas, tiveram relativamente pouco impacto na percepção dos usuários e na sua habilidade de utilizar a cena para realizar tarefas. Outras referências, como sombras, tiveram impactos muito mais significativos.

- Diferentes referências tiveram diferentes impactos quando os usuários realizaram tarefas diferentes, e algumas vezes chegaram até a confundir os usuários. Por exemplo, perspectiva linear aumentou em $29 \%$ a eficiência dos usuários no posicionamento de objetos, porém diminuiu em $36 \%$ a eficiência com relação à rotação dos objetos.

Estes resultados sugerem que ao escolher algoritmos diferentes para gráficos tridimensionais interativos, devemos prestar atenção nas referências utilizadas. Neste caso, tentar incluir todas as referências possíveis pode não ser vantajoso. Além de ser mais complexo e necessitar de computadores mais poderosos, pode também confundir e atrapalhar os usuários, dependendo da tarefa que estiverem realizando.

\subsubsection{Referências binoculares}

Referências monoculares não são tão convincentes quanto as referências binoculares, que podem criar uma imagem muito mais convincente, desde que ambos os olhos sejam usados. A aparência de profundidade que percebemos quando utilizamos ambos os olhos é 
chamada de estéreopsis [Smith93a], e ocorre quando o cérebro combina as duas imagens um pouco diferentes que recebe de cada olho e cria uma única imagem com o efeito de profundidade. A figura 3.5 ilustra este efeito.

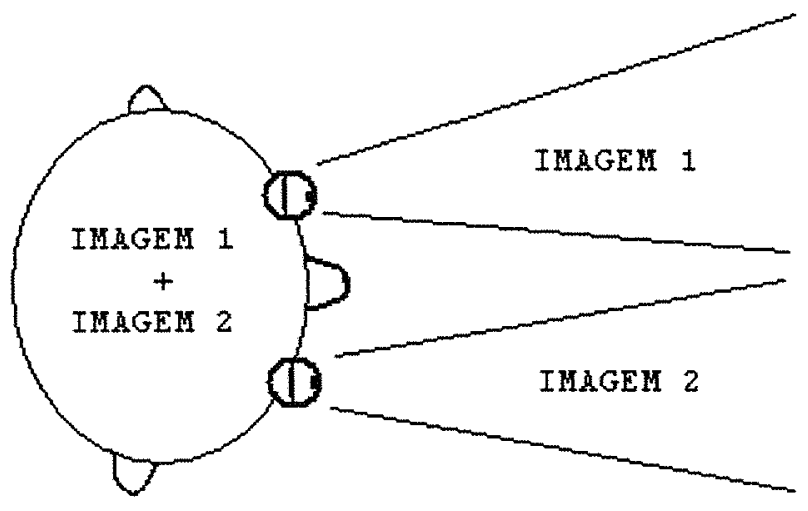

Figura 3-5

O efeito de estéreopsis pode ser simulado artificialmente através do uso de equipamentos especiais, como por exemplo óculos de realidade virtual, que enviam uma imagem bidimensional para cada olho. O cérebro as combina em uma imagem tridimensional. Apesar de as referências binoculares serem geralmente mais eficientes na criação de imagens tridimensionais do que as referências monoculares, existe uma pequena parcela da população cujo cérebro não tem a capacidade de realizar estéreopsis; estas pessoas utilizam apenas referências monoculares para obter imagens tridimensionais [Mansson98a].

As referências binoculares em si não necessitam das referências monoculares para fornecerem um efeito tridimensional. Um bom exemplo de como o cérebro pode realizar estéreopsis sem o auxílio de referências monoculares são os estereogramas. Estas são imagens que, à primeira vista, são apenas conjuntos aleatórios de pontos. Porém, ao nos 
concentramos na imagem, surge aos poucos uma imagem tridimensional, que é resultado da estéreopsis feita pelo cérebro.

\subsection{Realidade Virtual}

Existem inúmeras definições sobre o que o termo realidade virtual realmente significa. Sendo assim, não existe uma única definição que seja globalmente aceita. Porém, um uso comum de aplicações que utilizam realidade virtual é dar ao usuário uma ilusão de imersão em um ambiente artificial, gerado pelo computador. Acredita-se que o termo originou-se das obras literárias de William Gibson, escritas no início dos anos 80, nas quais ele descreve um ambiente artificial criado por computador, chamado de ciberespaço. O termo é geralmente usado para se referir a qualquer mundo virtual representado em um computador, mesmo que seja uma simples representação em modo texto.

Geralmente acredita-se que realidade virtual significa algo "falso" ou "irreal", e que "realidade" refere-se apenas ao mundo real. Isto não está totalmente correto. A definição de virtual é "que não existe como realidade, mas sim como potência ou faculdade" [Wei98a]. Realidade significa "qualidade do que é real". Usando ambas definições, podemos afirmar que realidade virtual significa "algo que não existe como realidade, mas que tem qualidade do que é real". Isto é exatamente o efeito desejado quando utiliza-se realidade virtual. De fato, não existe nenhuma "regra" que dite que o mundo virtual deva parecer-se com o mundo real. Porém, na maioria dos casos, o uso de realidade virtual implica em tentar emular o mundo real.

Realidade virtual também é por vezes chamada de realidade virtual imersiva. Neste caso, utiliza-se equipamentos especiais que são capazes de substituir todos os sentidos humanos por outros artificiais. Por exemplo, o sentido de visão é simulado quando o usuário usa óculos especiais que ocupam todo o seu campo de visão, transmitindo imagens do mundo 
virtual e efetivamente fazendo com que o usuário sinta-se imerso no mundo virtual. Aplicações que utilizam este tipo de realidade virtual geralmente também utilizam outros dispositivos, como fones de ouvido capazes de passar ao usuário a exata posição do som [Rob93b]. Deste modo, acredita-se que o esforço para criar ambientes virtuais que pareçam reais é bem menor quando faz-se uso da realidade virtual imersiva. Não há a necessidade, por exemplo, de criar elementos que permitam o usuário rotacionar um objeto no mundo virtual: basta que o usuário estenda a mão, apanhe o objeto, e o rotacione assim como o faria no mundo real, assumindo que pelo menos os sentidos de visão e tato estejam sendo emulados pelo programa.

\subsubsection{Realidade Virtual Não-imersiva}

Realidade virtual não-imersiva, também por vezes chamada de desktop virtual reality, é um subconjunto da realidade virtual que não necessita de equipamentos especiais. Neste caso, o usuário é também colocado em um ambiente virtual tridimensional, porém toda a visualização e manipulação é feita através de equipamentos convencionais, como monitor, mouse e teclado [Coo97a]. O monitor é um equipamento capaz de exibir apenas imagens bidimensionais. Sendo assim, utilizam-se referências monoculares para obter-se a ilusão de tridimensionalidade [Rob93a]. Apesar de este fato, por si só, não prejudicar muito a ilusão de tridimensionalidade, monitores convencionais oferecem um campo limitado de visão, o que pode prejudicar a navegação do usuário [Rud98a, Rud99a]. A figura 3.6 mostra uma cena exibida em duas dimensões que utiliza várias referências monoculares para obter a ilusão de tridimensionalidade.

Neste tipo de realidade virtual, também é possível simular outros sentidos, como por exemplo a audição. Neste caso, fones de ouvido ou caixas de som comuns são usadas para fornecer referências aurais ao usuário. Por exemplo, objetos distantes emitem sons mais baixos. Por exemplo, com as placas de som Soundblaster e compatíveis, que são 
equipamentos relativamente comuns em computadores pessoais, é possível emular sons vindo de diferentes direções e distâncias [Cre03a].

Existem também equipamentos, utilizados em computadores pessoais, que fornecem ao usuário seis eixos de movimentação, ao invés dos dois eixos fornecidos por um mouse convencional. O Spaceball 5000 é um exemplo deste tipo de equipamento, mostrado na figura 3.7, à direita. Outros equipamentos, geralmente chamados de force feedback devices, são capazes de fornecer alguma informação de tato ao usuário, como por exemplo impactos. Um exemplo deste tipo de equipamento é o Microsoft Sidewinder Force Feedback, também mostrado na figura 3.7, à esquerda.

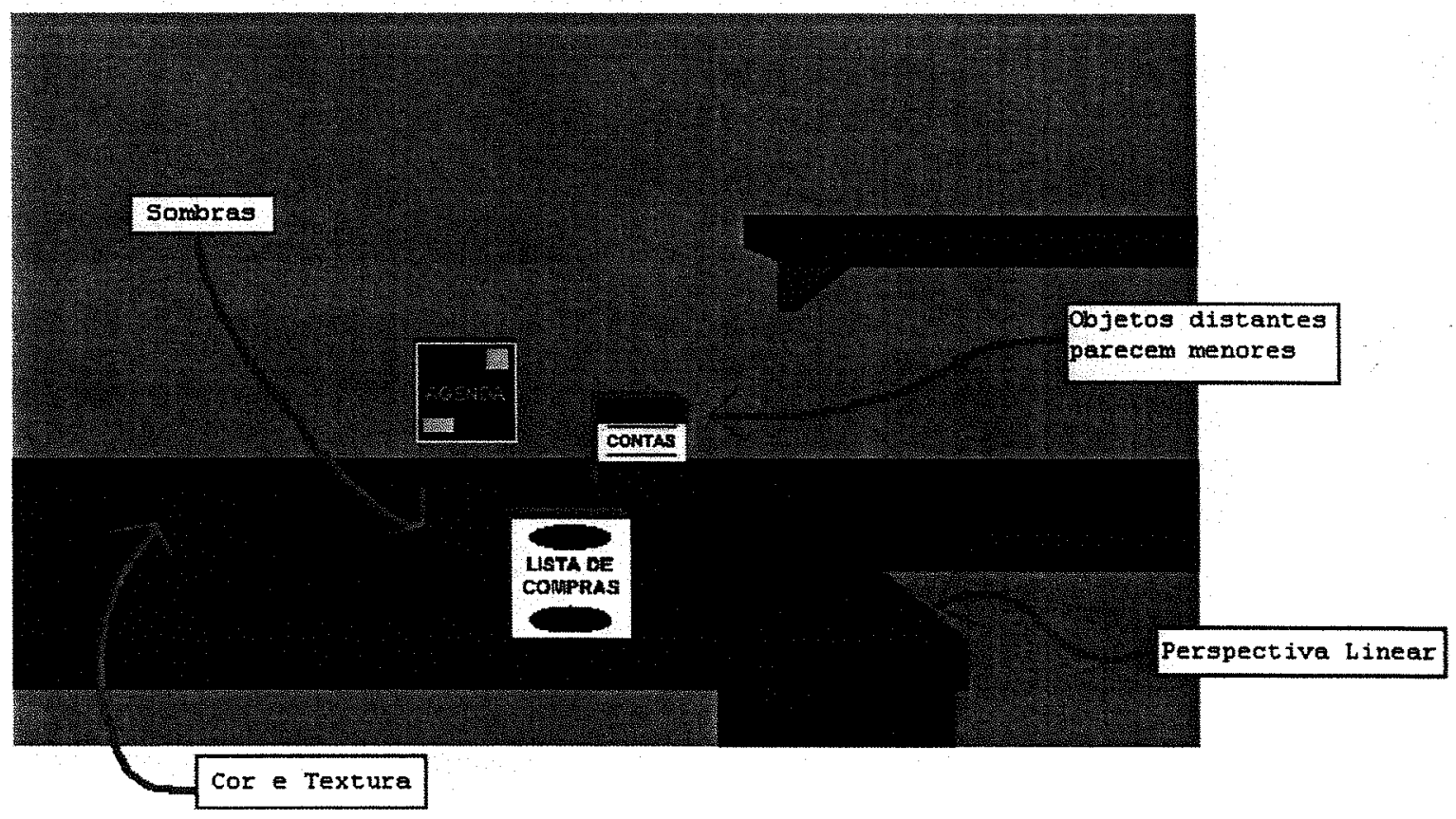

Figura 3.6 - Auxílios monoculares em uma cena 

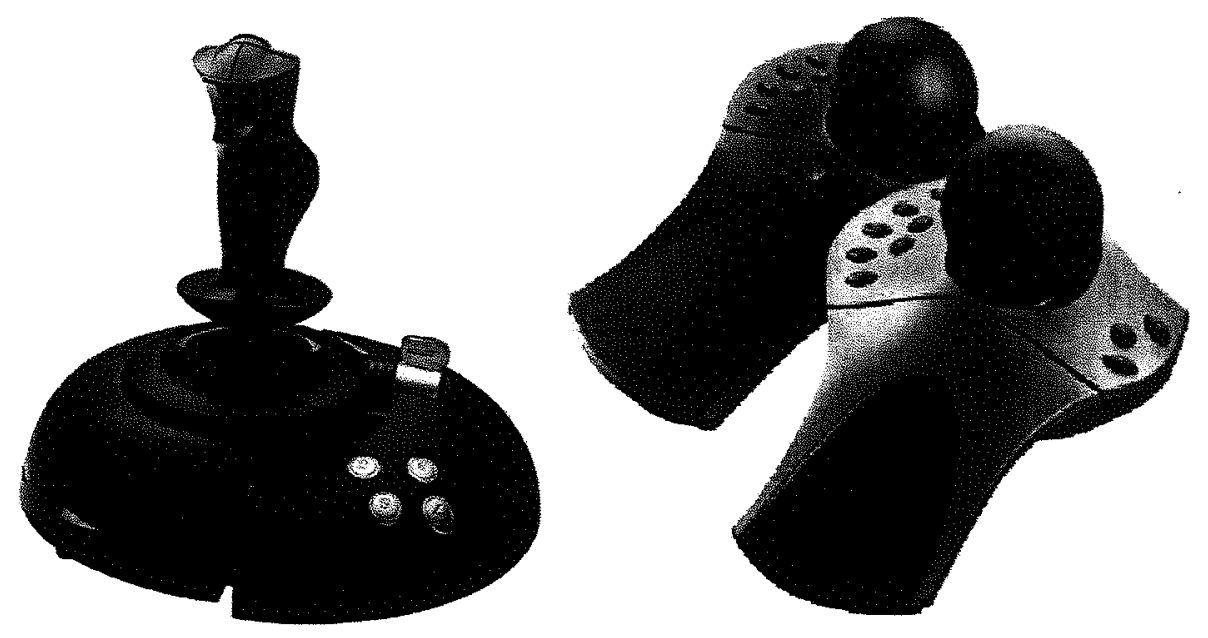

Figura 3.7 - Equipamentos para movimentação em três dimensões

Geralmente estes dispositivos de entrada são complementares ao dispositivos normais. Por exemplo, no caso do Spaceball 5000, ele pode ser utilizado na mão esquerda, para rotacionar um objeto, enquanto a mão direita do usuário continua manipulando o mouse para selecionar menus, por exemplo. No caso específico do Spaceball, o usuário obtém movimento empurrando e puxando levemente a bola do equipamento em várias direções. Apesar de poderem facilitar a manipulação de objetos em três dimensões, estes tipo de dispositivos não costumam ser muito comuns, e os seus preços relativamente altos impediram que fossem amplamente adotados pelos usuários comuns. 


\section{Capítulo 4}

\section{Aspectos cognitivos em interfaces de usuário}

Projeto de interface de usuário é uma atividade que envolve vários campos do conhecimento, e pesquisas no campo de psicologia podem ser especialmente úteis. Um melhor entendimento de como humanos percebem e interagem com o seu ambiente pode contribuir para o projeto de melhores interfaces. Sendo assim, este capítulo é uma breve introdução a alguns aspectos cognitivos de navegação e interação.

\subsection{Navegação}

Navegação era originalmente definida como o processo de se mover através de um ambiente. Darken e Silbert aumentaram esta definição de navegação para incluir o processo de wayfinding, isto é, o processo de determinação de um caminho a ser percorrido. Navegação foi então definida como o processo de determinar e percorrer um caminho através de um ambiente. Esta definição foi então ampliada mais uma vez para permitir a inclusão de sugestões e ajudas artificiais, como, por exemplo mapas, que são algumas vezes necessários para que seja possível navegar com sucesso um ambiente sem se perder [Dar93a].

Sendo assim, podemos então definir navegação como sendo o processo pelo qual pessoas controlam seus movimentos usando sugestões e ajudas artificiais tais como mapas, para que possam chegar em seus objetivos sem se perderem. Um grande problema para usuários de todas as formas de navegação é como manter conhecimento de sua localização e orientação enquanto movem-se pelo espaço. 
Quando falamos de navegação em sistemas de computadores, aspectos importantes a serem considerados são mapas cognitivos e habilidades espaciais. Darken e Silbert mostraram que pessoas usam estratégias de navegação do mundo real em mundos virtuais, como por exemplo usar mapas cognitivos como auxílio na navegação [Dar93a]. De acordo com Höök e Dahlbäck, diferenças individuais em habilidades espaciais afetam a habilidade dos usuários para navegar em sistemas de computador [Höök97a].

\subsubsection{Mapas cognitivos}

O termo "mapa cognitivo" é usado para descrever uma representação mental de informação espacial. Apesar de não possuirmos ainda conhecimentos concretos de como o conhecimento espacial é estruturado na mente humana, sabe-se que a representação de conhecimento espacial é afetada pelo método usado para obtê-la [Dar01a, Hun99a]. Por exemplo, conhecimento adquirido através de navegação direta em um ambiente é diferente de conhecimento adquirido através de mapas. Para localizar algo em um ambiente virtual, usuários que utilizam dispositivos não-imersivos, como monitores, tendem a ter pior desempenho do que aqueles que utilizam dispositivos imersivos, devido à capacidade limitada do monitor em fornecer um campo de visão adequado [Rud98a, Rud99a]. Isto ocorre porque, como já foi dito, humanos tendem a utilizar, mesmo em mundos virtuais, as mesmas técnicas de navegação do mundo real. Qualquer fator que limite o uso destas técnicas dificulta a navegação dos usuários [Vin99a]. Além disso, o movimento no espaço virtual muitas vezes pode ser discreto, enquanto o movimento no mundo real é contínuo [Spe99a]. A comunicação com a interface através do mouse e teclado permite que o usuário vire, pule e mova-se através do ambiente. O usuário também tem a possibilidade de ver o ambiente virtual através de diferentes perspectivas [Sat95a]. Consequientemente, usuários que "visitam" um mundo virtual muitas vezes encontram situações nas quais eles não serão capazes de confiar ou até mesmo sequer utilizarem em habilidades de navegação adquiridas no mundo real. Daí surgem os problemas de navegação virtuais conhecidos, como desorientação, perda da localização e dificuldade a retornar a um lugar visitado 
anteriormente. Isto é muito relevante, pois pode levar os usuários a ficarem frustrados com a interface e até mesmo abandoná-la [Nash00a].

Para tornar mais clara a definição de "mapa cognitivo", daremos um exemplo de como pássaros navegam. É fato conhecido que pássaros tem grande habilidade de navegação, especialmente durante migrações, e existem evidências que pássaros usam habilidades de percepção para detectar e codificar aspectos do ambiente à sua volta. Acredita-se que pássaros criem seus mapas cognitivos utilizando uma técnica chamada de landmarking, através da qual marcos na paisagem são utilizados [Dar93a]. Estes marcos podem ser visuais, acústicos ou até mesmo olfatórios. Recursos tais como "abrigo" e "água" são codificados junto com informação sobre o caminho mais curto e seguro entre dois pontos. A altitude na qual voam possibilita que relações espaciais entre os diversos marcos seja refinada uma vez que tais marcos podem ser vistos simultaneamente.

Assim como os pássaros, acredita-se que humanos também formem mapas cognitivos de seus ambientes para uso em navegação. Tais mapas cognitivos são criados utilizando-se componentes genéricos como caminhos, marcos, nós, distritos, áreas, e outros. De acordo com Darken e Sibert, os recursos usados para criar estes mapas são, entre outros:

- Caminhos: separadores, estradas e passagens;

- Bordas: separadores, paredes e cercas;

- Marcos: objetos que estão em grande contraste com o ambiente à sua volta, tal como a torre de uma igreja;

- Nós: seções do ambiente com características similares. Por exemplo, um grupo de ruas com o mesmo tipo de poste de luz;

- Distritos: seções logicamente e fisicamente distintas.

De acordo com Chen e Czerwinski, o simples fato de se adicionar itens, como por exemplo bordas, aumenta o desempenho dos usuários de interfaces de forma significativa [Che98a]. 


\subsubsection{Habilidade Espacial}

Foi demonstrado que a habilidade espacial dos usuários pode tanto limitar ou ajudar o uso de sistemas de computadores. As diferenças individuais de cada um, assim como o método de navegação utilizado por cada pessoa, são importantes e significantes fatores que influenciam no desempenho de cada usuário [Höök97a].

Com relação à habilidade espacial, temos três aspectos diferentes que são os mais pesquisados: orientação, visualização e relação [Sat95a]. Apesar disto, ainda não chegouse a um consenso universalmente aceito sobre o verdadeiro significado de orientação espacial. Höök concluiu que a habilidade espacial de um usuário afeta significativamente sua habilidade de navegar grandes estruturas de arquivos. Resultados similares também foram encontrados com relação à navegação em hipermídia, assim como, por exemplo, uma coleção não-linear de textos agrupados e através da qual pode-se navegar. Neste sistema, o melhor usuário foi quase que 20 vezes mais rápido do que o usuário mais lento [Höök97a].

\subsection{Interação}

Interação significa como humanos trocam informações com o ambiente: porque geralmente escolhemos focalizar certos elementos (atenção), como sabemos o que podemos fazer com estes elementos (capacidades) e como filtramos informações redundantes (abstração). 


\subsubsection{Atenção}

A atenção dos humanos concentra-se principalmente em diferenças na aparência visual, como, por exemplo, cor, textura, forma, tamanho, localização, assim como a habilidade para perceber movimentos [Wiss98a].

A localização de um objeto também determina a quantidade de atenção que nós dispensamos ao mesmo. Objetos localizados no centro do nosso campo de visualização tendem a receber mais atenção do que objetos localizados na periferia do campo de visão. Além disso, se nossa atenção focaliza algo em particular, elementos ao redor e que se encontram perto do foco da atenção também irão automaticamente receber mais atenção. Outro fato é a nossa habilidade de registrar movimento, que causa, por exemplo, que objetos piscantes capturem nossa atenção, tornando assim mais difícil focalizar nossa atenção em outros objetos. Essa habilidade foi herdada de nossos ancestrais para os quais era muito importante notar movimentos que podiam significar perigo ou comida em potencial.

\subsubsection{Capacidades}

Capacidade, também conhecido como affordance, se refere às propriedades percebidas por nós, e as propriedades atuais dos objetos, especialmente aquelas propriedades fundamentais que determinam como as coisas podem ser utilizadas [Norman 1988]. Em outras palavras, capacidade é o auxílio que o próprio objeto nos dá para que possamos perceber o que pode ser feito com ele. Um botão nos passa a idéia de pressioná-lo, uma maçaneta de girá-la, uma bola de arremessá-la. O que o objeto nos passa através de capacidades consiste basicamente do modelo mental da pessoa, de aspectos culturais, e de outros fatores. 
A psicologia da causalidade também é utilizada conforme interagimos com o ambiente, o que significa que o resultado percebido de uma ação parece ser causado por aquela ação. Mas isto também pode agir contra o usuário. Por exemplo, um certo erro pode nos passar a impressão que foi causado por uma certa ação, quando na realidade não o foi. Esse tipo de causalidade falsa pode ocorrer em interfaces de usuário devido a projetos mal feitos [Norman1988a].

\subsubsection{Abstração}

A quantidade de dados que passa através dos sentidos humanos é tão grande que somos forçados a filtrar a grande maioria, para que possamos nos concentrar nos elementos que consideramos ser importantes. Porém, toda essa "filtragem de dados" pode remover certos contextos globais importantes e nos deixar desorientados. Uma solução para reter estes contextos globais é organizar os dados de tal forma que possamos obter maior compreensão, mesmo que isto signifique uma menor capacidade para absorver detalhes. Abstração significa uma transformação na qual "muitos dados" transformam-se em apenas "um dado", baseado em possíveis variantes que um objeto pode ter. Deste modo, estas variantes são transformadas em uma única forma invariável, o que diminui a quantidade de dados a ser analisada. Isto pode ser ilustrado pela lei Gestalt da percepção [Smith1993a].

A lei Gestalt da percepção é um jeito de descrevermos como os humanos relacionam símbolos visuais, agrupando-os em grupos que são similares entre si e que formam estruturas que são apenas sugeridas durante a visualização. De fato, a psicologia Gestalt é um campo da psicologia que enfatiza padrões de organização. "Gestalt" é uma palavra em alemão, que significa "um todo organizado". A idéia básica é que o todo é maior que a soma das partes. Psicólogos que seguem a linha Gestalt catalogaram uma série de leis de agrupamento relacionadas à percepção, que oferecem explicações sobre o funcionamento do processamento visual, assim como a natureza da representação visual. Tais psicólogos 
sugerem que grupos de pessoas agrupam e interpretam estímulos de acordo com quatro leis de organização: proximidade, similaridade, fechamento e continuidade [Smith1993a].

O princípio de continuidade sugere que elementos que estão mais perto tendem a ser agrupados juntos. O princípio de similaridade significa que objetos serão colocados em um mesmo grupo devido a características comuns que têm entre si. Outra lei de organização Gestalt é chamada de fechamento. Ela dita a habilidade de vermos objetos que estão aparentemente desorganizados ou não tem relação alguma entre si como sendo parte de um todo, construindo assim um retrato completo que é composto de material incompleto.

A última lei Gestalt é o princípio da continuidade, que lida com objetos que definem curvas ou linhas suaves. Uma boa continuidade é um princípio de organização tão forte que quando a figura volta para o seu estado original, outras formas de organização tendem a ser "perdidas" e substituído pela lei de continuidade. Os princípios de similaridade, proximidade e fechamento são ilustrados na figura 4-1 abaixo.

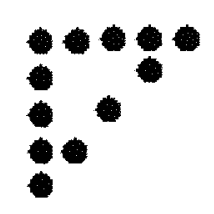

Similaridade

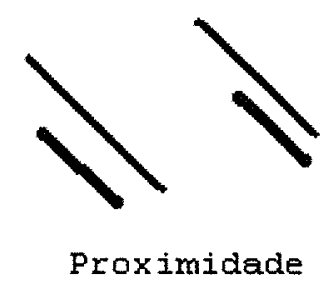

Proximidade

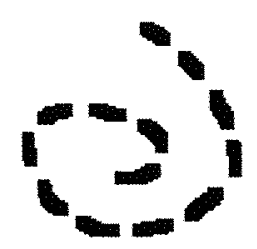

Continuidade

Figura 4-1 


\section{Capítulo 5}

\section{Áreas de aplicação de interfaces tridimensionais}

Este capítulo mostra alguns exemplos de áreas onde interfaces tridimensionais já estão sendo utilizadas. Algumas destas áreas são visualização de informação, simulação, navegação, entretenimento e marketing.

\subsection{Visualização de informação}

Sistemas baseados na metáfora da área de trabalho (desktop) geralmente usam metáforas espaciais, porém sem tirar total proveito delas uma vez que os ambientes são na realidade bidimensionais. $\mathrm{O}$ uso de metáforas especificamente tridimensionais, como salas, casas e cidades virtuais, por exemplo, podem permitir que no mundo virtual seja tirado proveito das mesmas habilidades espaciais que utilizamos no mundo real. O conceito de espaço em três dimensões é muito importante na nossa vida diária, e a simulação de espaços tridimensionais em ambientes virtuais pode ser muito vantajosa. Tal fato é exemplificado no File System Navigator, descrito por Keith Andrews [And94a].

O File System Navigator (FSN) é um protótipo desenvolvido pela empresa Silicon Graphics. Ele é utilizado para visualizar um sistema de arquivos Unix exibindo o conjunto de arquivos como uma paisagem tridimensional, na tentativa de fazer uso das capacidades espaciais do usuário. A figura 5.1 mostra uma tela deste programa.

O programa utiliza componentes de interfaces bidimensionais, porém exibe o sistema de arquivos em três dimensões. Diretórios são representados hierarquicamente por pedestais colocados em um plano, e a altura de cada um é proporcional ao tamanho dos arquivos contidos dentro de cada diretório. A cor indica quando foi a última atualização. Blocos menores no topo de cada pedestal representam os arquivos em cada diretório. Estes são 
conectados por fios, através dos quais é possível navegar. Quando clica-se no arco de um subdiretório, o usuário é transportado através do espaço para aquele subdiretório específico. Um clique em um bloco de arquivos traz um foco virtual que marca o bloco; um duplo clique abre o arquivo.

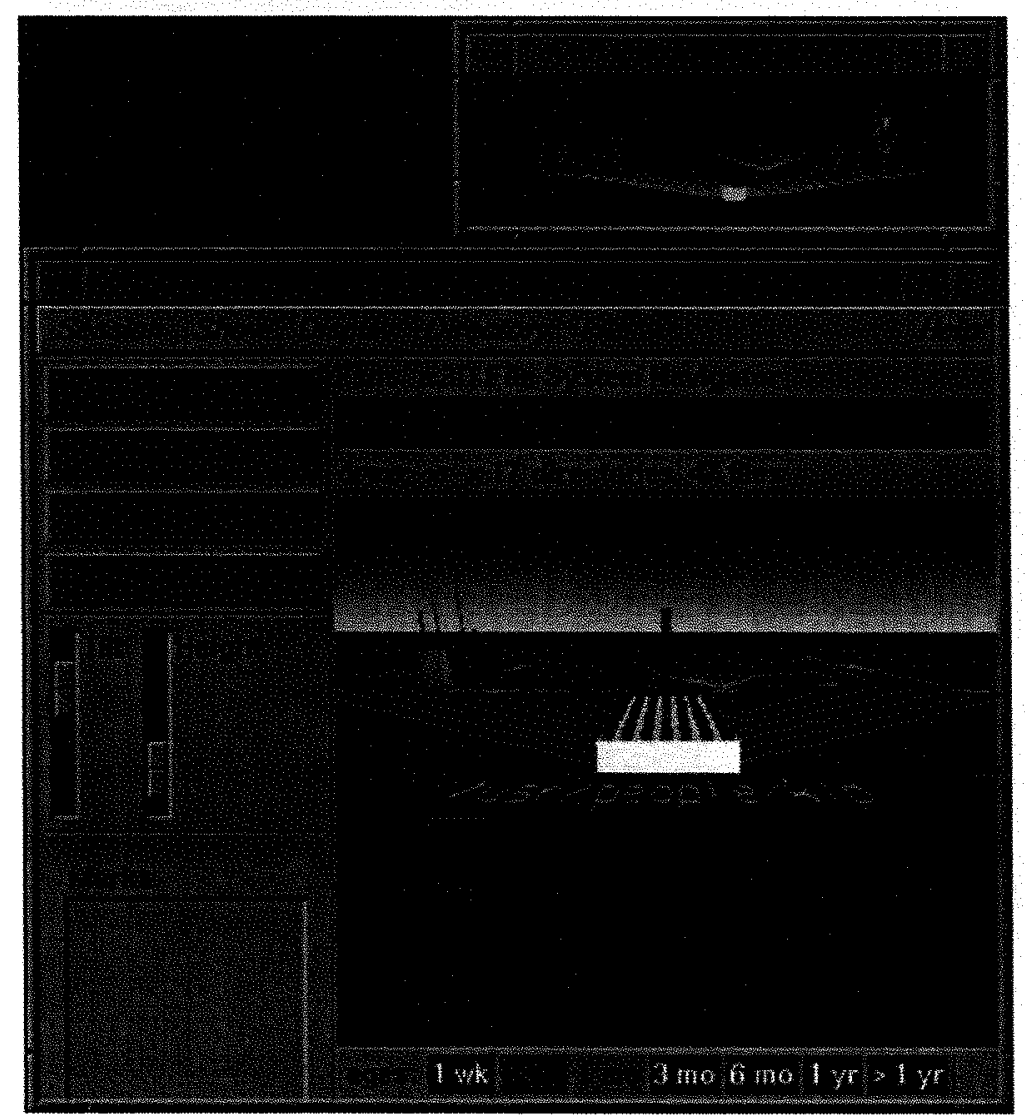

Figura 5.1 - File System Navigator

O protótipo roda em sistemas IRIX, da Silicon Graphics, e pode ser obtido no endereço http://www.sgi.com/fun/freeware/3d navigator.html 


\subsection{Simulação}

Um objetivo comum de aplicações como simuladores de vôo é fornecer um ambiente artificial que parece e reage como se fosse um ambiente real. Neste tipo de aplicação, interfaces tridimensionais são usadas para criar uma experiência imersiva e realista para o usuário.

\subsubsection{Túnel Virtual de Vento}

O Túnel Virtual de Vento, ou Virtual Wind Tunnel, da NASA, permite que cientistas visualizem propriedades de fluxo de ar e pressão utilizando conjuntos computacionais de dinâmica de fluido [Ded97a, Bry91a].

O túnel virtual de vento comporta uma variedade de técnicas de visualização. A maioria destas técnicas é projetada para permitir que o pesquisador movimente as visualizações, explorando assim os fenômenos de uma certa região do espaço. Para permitir esta manipulação direta, cada técnica de visualização precisa estar associada a um ponto no espaço. Esta localização é então usada para determinar qual os dados que devem ser exibidos. A figura 5.2 mostra um usuário superimposto a visualização do túnel virtual de vento.

Existem vários aspectos do túnel virtual de vento que não são facilmente realizados através de interfaces tridimensionais. Nestes casos, optou-se por utilizar elementos de interfaces gráficas bidimensionais, que foram integrados no sistema e trabalham juntos com os elementos tridimensionais.

Toda a interação com o ambiente é feita através de uma luva especial, que o usuário utiliza para acessar a interfaces. Cada gesto corresponde a um comando. Um pequeno monitor é 


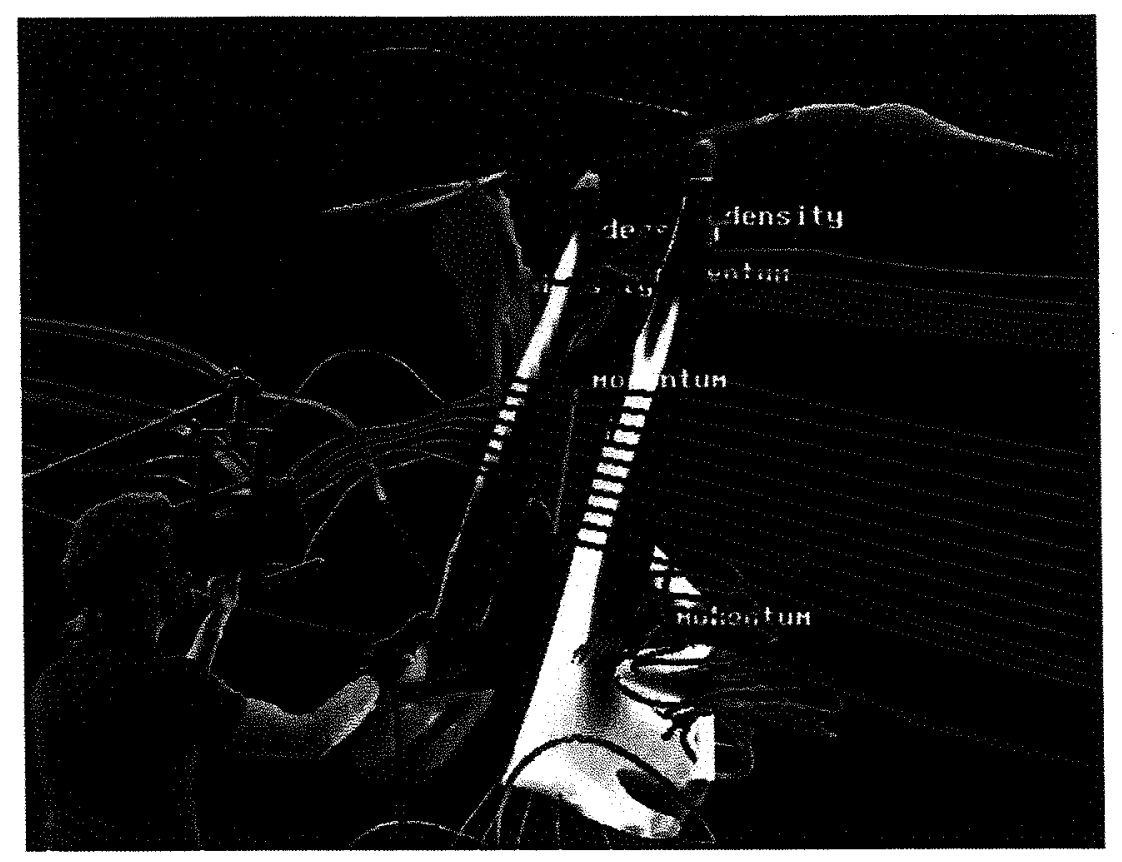

Figura 5.2 - Túnel virtual de vento

utilizado para simular o sentido de visão. O usuário utiliza este monitor aproximadamente da mesma maneira que utiliza um binóculo, ou seja, aproximando os olhos das lentes do monitor.

Todas as características do sistema, incluindo o manual, podem ser encontradas em http://www.nas.nasa.gov/Software/VWT/

\subsubsection{Simuladores de vôo}

Simuladores de vôo permitem que pilotos se familiarizem com novos aviões antes de verdadeiramente pilotá-los. Também permitem que pilotos experientes pratiquem procedimentos avançados que poderiam ser muito arriscados na vida real, como, por exemplo, falhas nas turbinas. Os simuladores de vôo mais complexos foram utilizados originalmente para propósitos militares e para treinamento de pilotos de vôos comerciais. 
De fato, uma grande parte da pesquisa em interfaces tridimensionais foi feita no campo da aviação. Wickens, Liang, Prevett e Olmos pesquisaram procedimentos de pouso usando tanto interfaces bidimensionais como tridimensionais [Wic96a]. Seus testes revelaram que os usuários tinham uma preferência um pouco mais acentuada pela interface bidimensional. Porém, isto contradiz uma pesquisa feita por St. John, Oonk e Cowen, que concluiu que os usuários tinham melhor rendimento usando uma interface tridimensional [Joh00a].

O Simulador de Movimento Vertical (Vertical Motion Simulator), construído pela NASA é um dos maiores simuladores tridimensionais existentes no mundo [Nas03a]. Ele consiste de uma cabine de avião em cima de uma plataforma. Esta última é apoiada em vários pistões que podem mover toda a cabine e assim simular movimento.

A cabine do simulador pode ser removida e trocada por outra. Deste modo, é possível colocar cabines diferentes que representem diferentes tipos de aviões. O piloto olha através do vidro da cabine e enxerga o mundo virtual que é exibido em uma grande tela que envolve a cabine. Neste caso, o simulador procura utilizar todos os sentidos do piloto para criar a ilusão do mundo virtual. Porém, aqui a interface física em si, ou seja, aquela com a qual o piloto interage diretamente, não é virtual, é nada mais do que uma cópia de uma cabine real. Alguns argumentam que este tipo de sistema não pode ser considerado uma interface tridimensional, na medida em que a cabine é tridimensional assim com um teclado ou mouse também é "tridimensional". A diferença, neste caso, é que a cabine é parte integral do mundo virtual, e é uma cópia exata do mesmo, enquanto que um teclado ou mouse, na maioria das vezes, não faz parte do mundo virtual.

\subsubsection{CAD (Computer Aided Design)}

Sistemas CAD são projetados para facilitar o processo de projeto para engenheiros e arquitetos quando estão criando ou manipulando modelos bidimensionais ou 
tridimensionais. Estes modelos podem ser rotacionados, ter sua escala mudada, podem ser editados e manipulados de várias maneiras. Estes sistemas exibem e manipulam plantas e projetos de objetos reais e podem, assim, fazer bom uso de gráficos tridimensionais.

Utilizando os projetos bidimensionais, estes programas podem criar objetos tridimensionais que permitem a visualização de, por exemplo, uma casa antes mesmo que esta comece a ser construída. Deste modo, podem ser usados para permitir que o usuário navegue através de uma construção virtual [Fun93a], sendo de grande auxílio para arquitetos e engenheiros. Apesar de a grande maioria destes sistemas funcionar em equipamentos tradicionais, já existem vários sistemas que utilizam realidade virtual para até mesmo melhorar a produtividade dos funcionários. Por exemplo, a empresa Embraer utiliza um sistema de realidade virtual que permite a visualização, através de equipamentos especiais, de um objeto tridimensional de vários ângulos. Este objeto pode ser manipulado de várias formas, e várias pessoas podem visualizá-lo ao mesmo tempo. A adoção deste sistema permitiu que a empresa reduzisse seu ciclo de desenvolvimento quase pela metade [Emb03a].

\subsubsection{Trabalho cooperativo através do computador}

Trabalho cooperativo através do computador (Computer Supported Cooperative Work) é o estudo de como pessoas trabalham juntas utilizando computadores. Aplicações típicas incluem correio eletrônico, sistemas de notificação, videoconferência, sistemas de batepapo virtual, jogos multijogador e aplicativos compartilhados, como por exemplo desenho colaborativo. Os benefícios potenciais de projetar computadores (e suas interfaces) para facilitar trabalho em grupo parecem ser grandes [Pre94a].

O Ambiente Interativo Virtual Distribuído (Distributed Interactive Virtual Environment), do Swedish Institute of Computer Science, é uma ferramenta que permite a construção de aplicativos em realidade virtual distribuídos, em uma rede heterogênea [Hag93a]. 
Conforme a figura 5.3 mostra, os usuários navegam em um espaço tridimensional e interagem com outros usuários. Cada ser virtual pode ser controlado por uma pessoa ou pode ser um processo automatizado. Para facilitar o reconhecimento das pessoas no mundo virtual, cada usuário é representado por um avatar, que é um ícone ou representação gráfica de um usuário no mundo virtual compartilhado, de maneira similar àquela utilizada em muitos sistemas VRML [Bro96a].

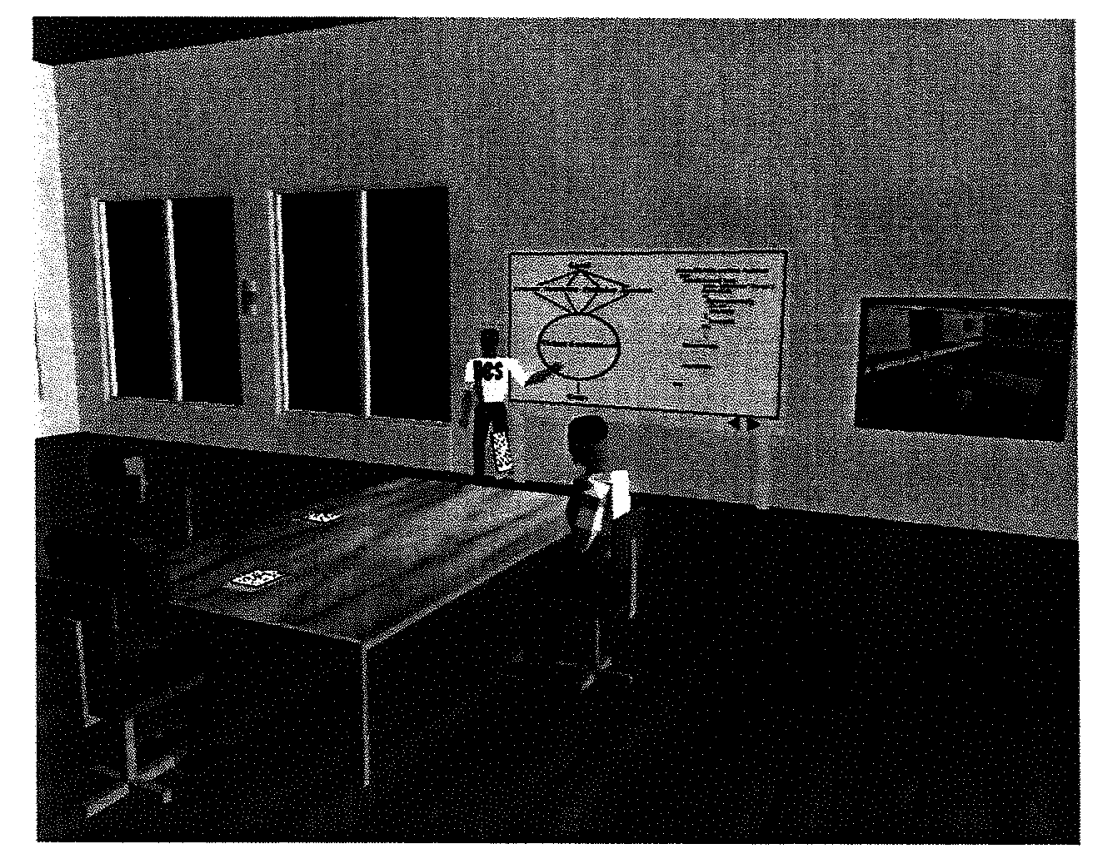

Figura 5.3 - Ambiente Interativo Virtual Distribuído

O usuário vê através de um aplicativo visualizador que faz toda a renderização do mundo virtual do ponto de vista dos olhos do avatar virtual. Quando a posição dos olhos muda, ou quando o usuário focaliza outro objeto, o ponto de vista é mudado pelo aplicativo. $\mathrm{O}$ aplicativo visualizador pode ser utilizado com uma gama de dispositivos, como, por exemplo, óculos especiais para realidade virtual. Outros equipamentos também podem ser acoplados ao sistema, que permitem que o usuário interaja mais naturalmente com o mundo virtual, como por exemplo luvas especiais. Sendo assim, o sistema analisa as ações e movimentos realizados por cada usuário, e então atualiza o mundo virtual. 
Neste tipo de mundo virtual, os usuários podem entrar e sair a qualquer momento. Os seres virtuais controlados pelo computador também podem reagir a certas condições, e podem adaptar a interface introduzindo ou removendo objetos virtuais.

\subsection{Substitutos para o gerenciamento de arquivos}

Recentemente, alguns produtos comerciais que têm como característica interfaces tridimensionais foram introduzidos. São produtos comerciais (que devem ser comprados pelo usuário), e na sua maioria têm como objetivo substituir o gerenciador de arquivos padrão do sistema operacional.

Um destes produtos é o Win3D, mostrado na figura 5.4. Seu conceito é similar ao do sistema 3D Rooms [Car91a], ou seja, arquivos e aplicativos podem ser colocados em diferentes salas virtuais. Por exemplo, programas de correio eletrônico e navegadores poderiam ser colocados na sala Internet, enquanto jogos e músicas poderiam ser colocados na sala Multimídia.

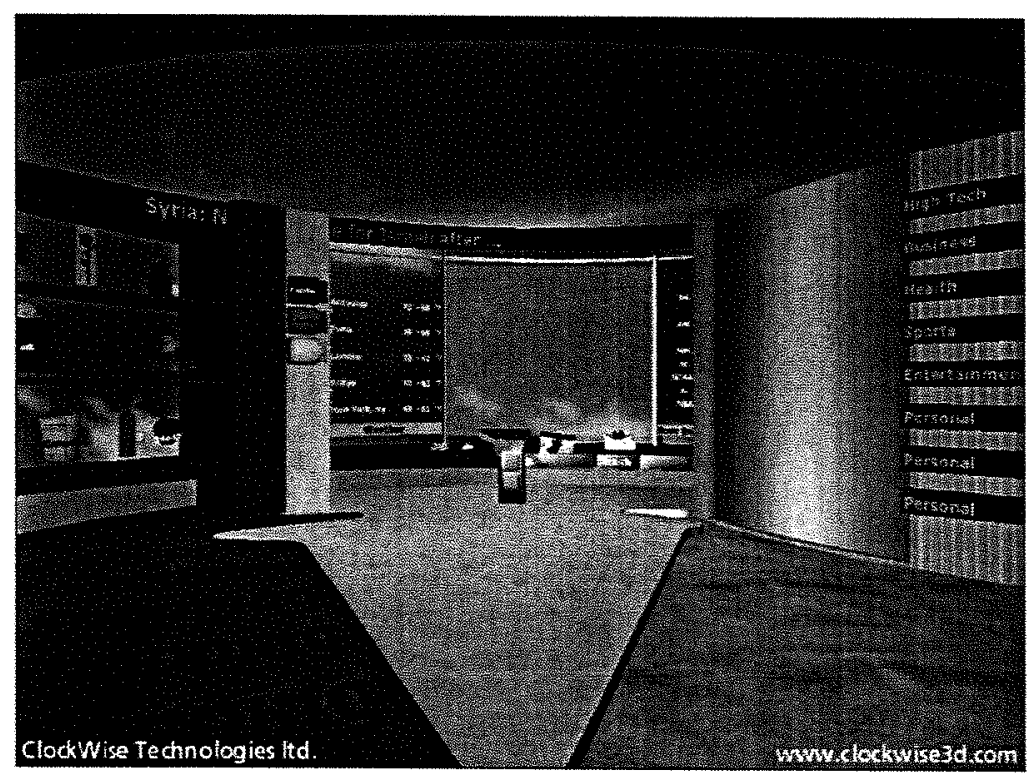

Figura 5.4 - Aplicativo Win3D 
O programa procura utilizar elementos de realidade virtual não-imersiva para simular o ambiente virtual. Toda a interação do usuário com o programa é feita através do mouse e teclado. Navegar pelo ambiente requer que o usuário esteja constantemente com o mouse em movimento, o que pode tornar a navegação cansativa e ineficiente.

Além disso, a interface do programa Win3D não é totalmente tridimensional. O programa ainda utiliza vários elementos bidimensionais, como janelas, para permitir algumas ações de manipulação dos arquivos. 


\section{Capítulo 6}

\section{Pesquisa em interfaces tridimensionais}

Apesar de interfaces tridimensionais já serem utilizadas em diversos setores, conforme mostrado no capítulo 5, ainda há uma quantidade de problemas que devem ser solucionados até que interfaces tridimensionais possam ser usadas em larga escala. Sendo assim, ainda existe uma série de pesquisas recentes que analisaram diferentes aspectos de interfaces tridimensionais. Este capítulo comenta algumas das pesquisas recentes mais importantes feitas neste campo.

Como as pesquisas nesta área são ainda relativamente recentes, as interfaces descritas abaixo ainda utilizam muitos elementos de interfaces bidimensionais, como por exemplo janelas. As interfaces descritas abaixo pertencem a um grupo que utiliza realidade virtual não-imersiva. Isto significa que seus ambientes virtuais são representados na tela bidimensional do computador, sem a utilização de equipamentos especiais, conforme descrito no capítulo 3. Além disso, toda forma de comunicação com a interface é feita usando-se o mouse e teclado. Existem pesquisas que concentram-se em interfaces cuja realidade virtual é imersiva [Bry96a]. Tais interfaces utilizam óculos, luvas e outros equipamentos especiais para dar uma melhor impressão ao usuário de que o mesmo encontra-se em um ambiente virtual. Nosso objetivo, porém, é a implementação de uma interface que possa ser usada em computadores comuns, desde que o mesmo possua algum subsistema gráfico (seja ele em hardware ou software). Deste modo, iremos apresentar aqui, para efeito de comparação, apenas pesquisas com interfaces cuja realidade virtual seja não-imersiva, com exceção daquela apresentada na seção 6.3, que é de interesse para este trabalho. 


\subsection{Data Mountain}

Data Mountain (figura 6.1) é uma interface gráfica projetada especificamente para aproveitar a memória espacial humana (isto é, a habilidade de lembrar onde colocamos algo no espaço tridimensional) [Rob98a]. Nesta interface, o usuário arranja thumbnails (pequenas fotos) de documentos em um plano inclinado. Efeitos tridimensionais são utilizados nos gráficos e no som para tentar tornar a interface o mais similar possível à organização de objetos no mundo real, porém usando simples interações bidimensionais com o uso do mouse. O sistema foi projetado com um ponto de vista fixo, de modo que o usuário não necessita realizar qualquer navegação pelo espaço virtual. Usuários podem identificar documentos através de seus thumbnails ou de pequenos textos que aparecem sobre os mesmos.

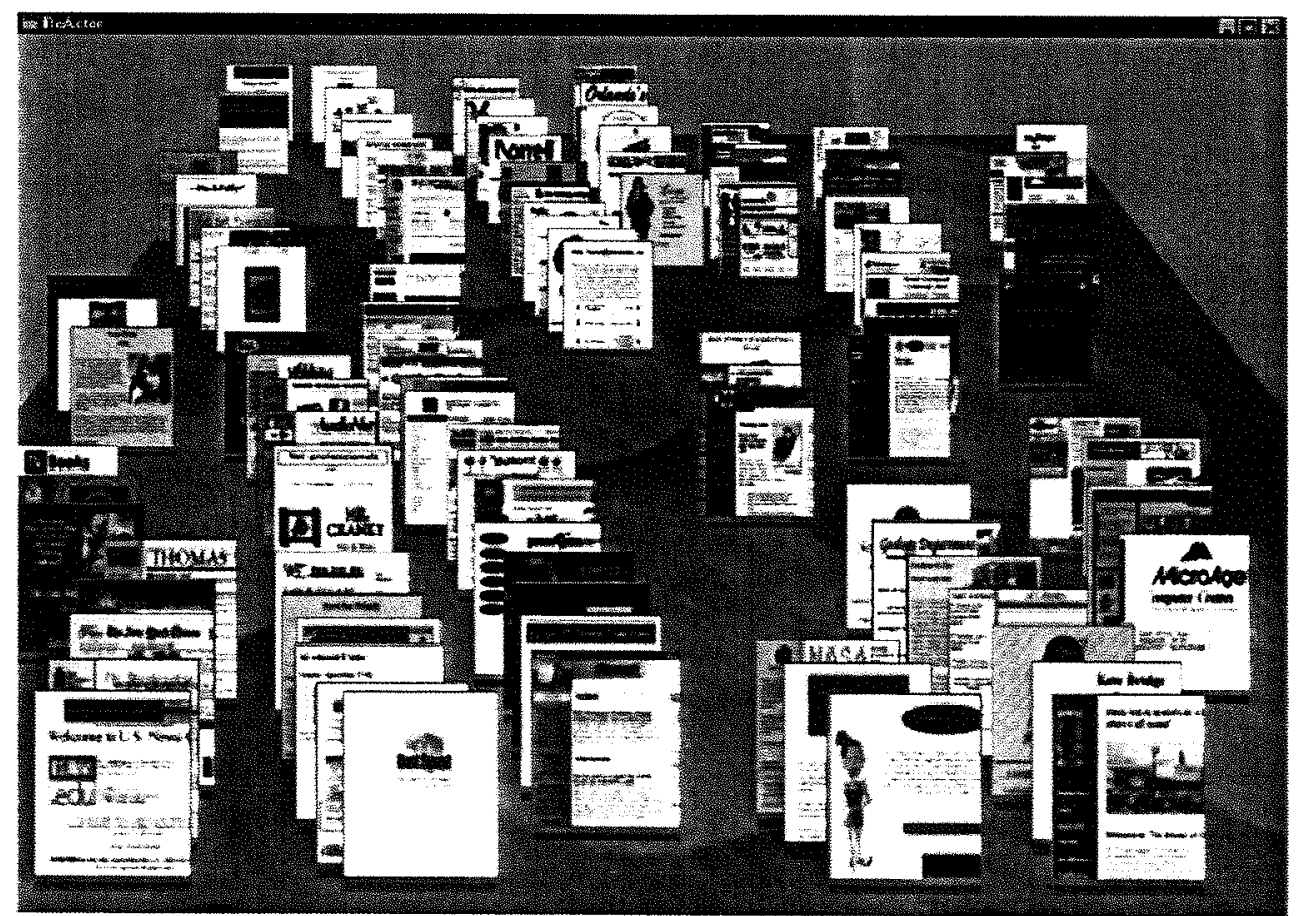

Figura 6.1 - Data Mountain 
Os pesquisadores notaram atitudes interessantes dos usuários do Data Mountain. Devido ao fato de ser um ambiente tridimensional virtual, alguns usuários, enquanto tentavam achar algum documento, falavam coisas do tipo "Está lá atrás em algum lugar" ou "Está logo aqui embaixo". Como foi feito uso da memória espacial, os pesquisadores notaram que o tempo para encontrar um documento, se comparado ao de uma interface bidimensional, foi significativamente menor.

Outras pesquisas mais recentes, porém semelhantes ao Data Mountain, mostraram uma insignificante melhora na eficiência quando a interface é bidimensional [Coc01a]. Porém, a maioria dos usuários costuma mostrar preferência pela interface tridimensional.

\subsection{Task Gallery}

A interface Task Gallery, desenvolvida no centro de pesquisas da Microsoft, é um gerenciador de janelas que utiliza gráficos interativos tridimensionais para fornecer suporte direto ao gerenciamento de tarefas e comparações de documentos [Rob00a]. As janelas e aplicativos dos usuários aparecerem como quadros em uma galeria de arte virtual, com as janelas em uso sendo exibidas em um pequeno palco no centro da tela. Múltiplos documentos e janelas podem ser selecionados e exibidos lado-a-lado usando o espaço tridimensional para fornecer uma ilusão de profundidade. Vide a figura 6.2.

Como é apenas um gerenciador de janelas, o Task Gallery pode exibir qualquer aplicativo Windows, usando um mecanismo de redirecionamento que automaticamente envia a entrada feita pelo usuário no ambiente tridimensional para o aplicativo correto.

Pesquisas feitas com o Task Gallery sugerem que esta interface auxilia o gerenciamento de tarefas, é intuitiva de usar e que a metáfora tridimensional traz à tona a memória espacial, o que ajuda a localizar documentos de maneira mais rápida. 


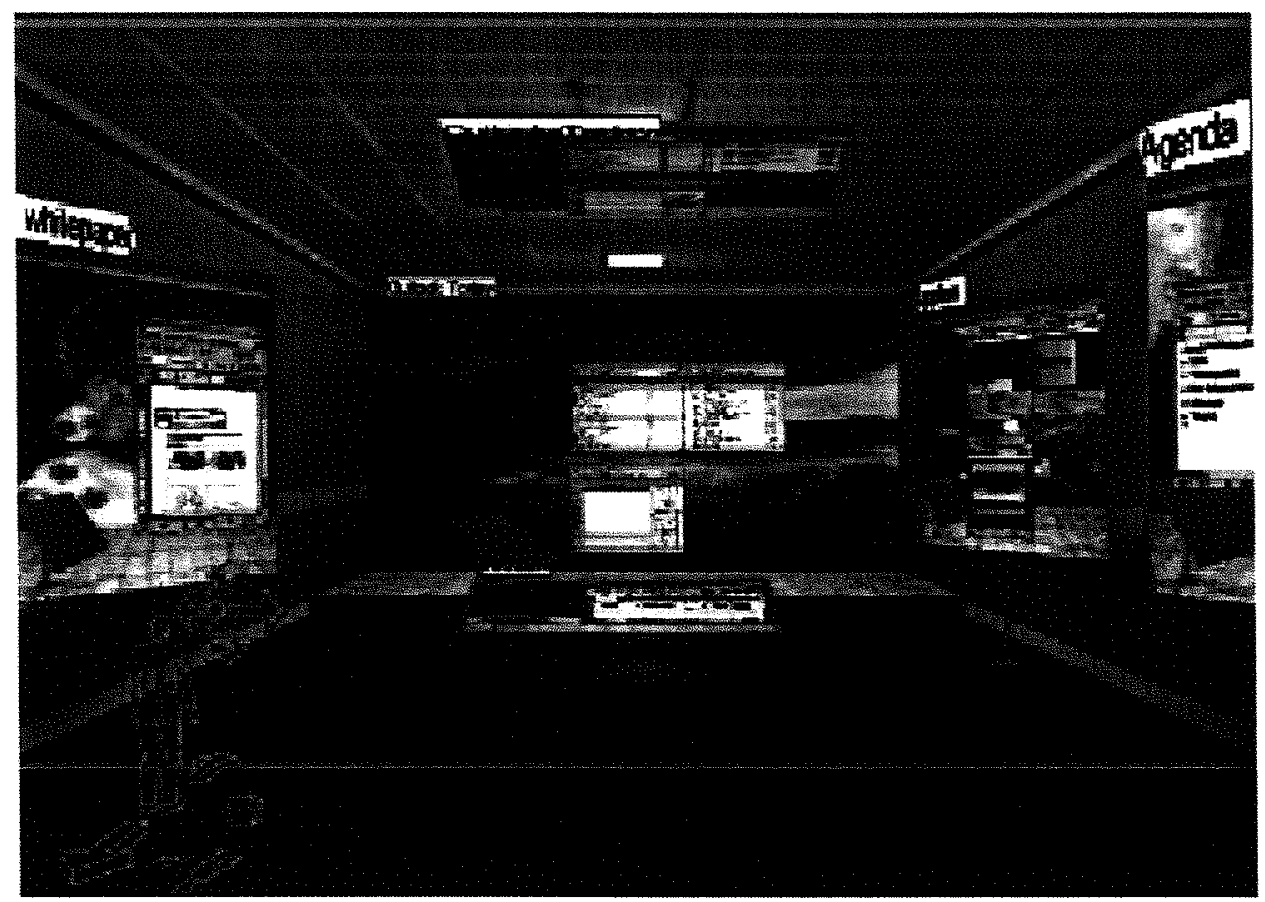

Figura 6.2 - Task Gallery

\subsection{Comparação direta entre 2D e 3D}

Outra pesquisa recente avaliou o impacto direto que uma terceira dimensão teria em usuários, não apenas em interfaces gráficas em computadores, mas também em interfaces físicas, como, por exemplo, um organizador de papéis [Coc02a]. Deste modo, foi possível avaliar se o resultado da pesquisa não foi influenciado de alguma maneira pelos computadores em si. A pesquisa também analisou interfaces " $2 \mathrm{D} 1 / 2$ ", ou seja, aquelas que têm uma aparência de profundidade, porém apenas permitem o movimento dos objetos em dois eixos. A figura 6.3 mostra um exemplo das interfaces utilizadas na pesquisa. 

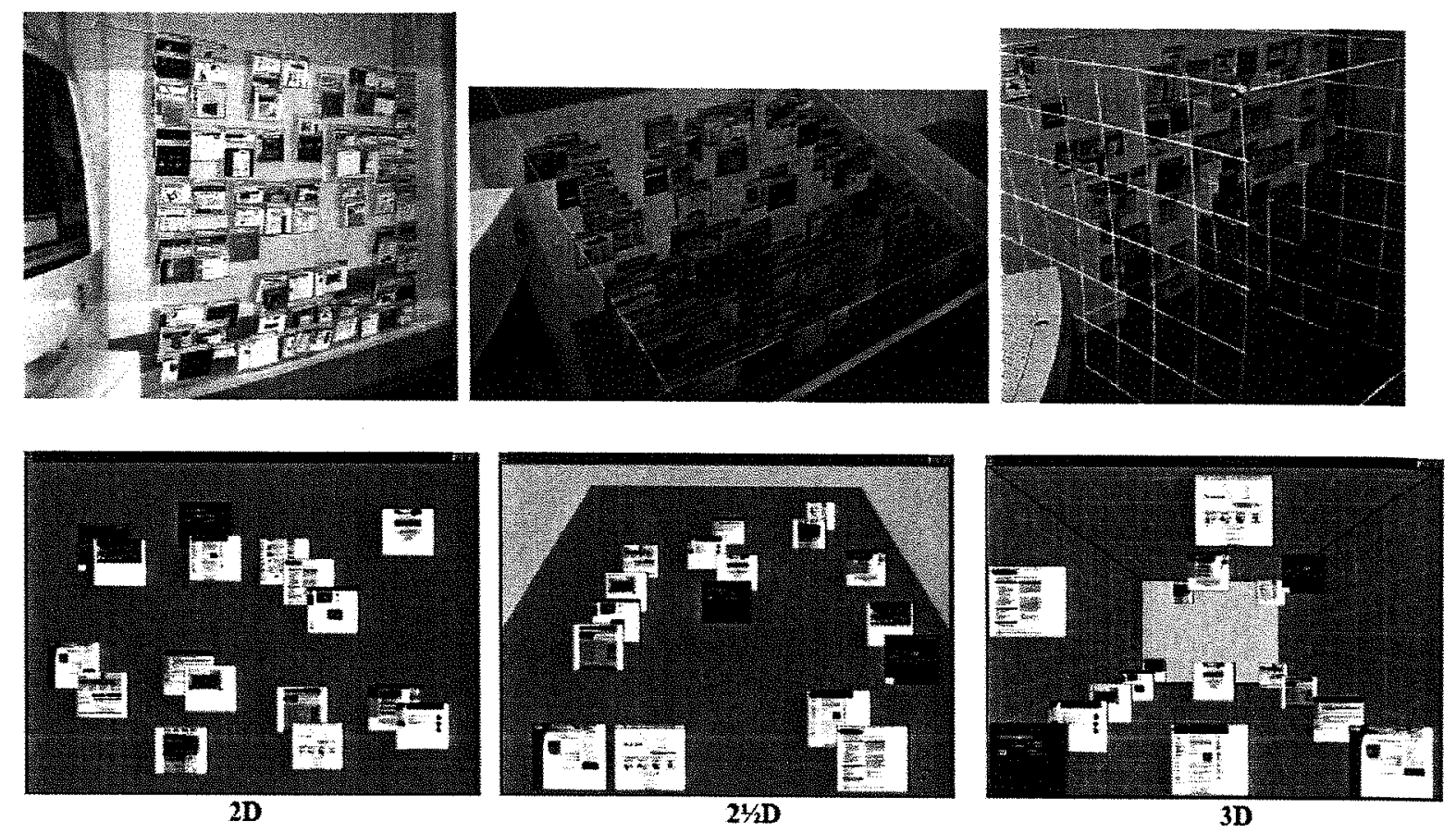

Figura 6.3 - Interfaces 2D, 2D 1/2, 3D

Outro detalhe importante deste experimento é o ponto de vista fixo do usuário. Conforme a pesquisa concluiu, ponto de vista fixos em interfaces tridimensionais podem reduzir muito a eficiência do usuário.

A eficiência dos usuários reduziu sistematicamente conforme utilizavam aumentava-se o número de dimensões da interface (2D, 2D 1/2 e 3D). Os usuários também indicaram que um número muito grande de documentos nas interfaces tridimensionais reduzia em muito a rapidez com a qual conseguiam encontrar documentos requisitados. Isto pode estar relacionado ao fato de o ponto de vista ser fixo nesta interface, o que poderia causar problemas de oclusão. Apesar disto, poucos usuários reclamaram deste fato quando utilizando a interface tridimensional. Isto foi o oposto da interface $2 \mathrm{D} 1 / 2$, onde suspeita-se ser a oclusão o maior motivo para a perda de eficiência, uma vez que os usuários precisaram constantemente mexer em documentos apenas para tentar encontrar algo que estivesse atrás do mesmo. Isto sem dúvida pode acarretar em perda de desempenho. 
A pesquisa também questionou se a interface física tridimensional era apropriada, pois ela restringia um pouco o movimento nos três eixos. Por exemplo, a menor distância entre objetos nesta interface era de 5 centímetros, enquanto que nas outras interfaces físicas era apenas de 2 centímetros.

A pesquisa concluiu que, para um número pequeno de documentos (até 99), interfaces bidimensionais permitem que usuários encontrem itens requisitados mais rapidamente.

\subsection{Comentário}

Conforme podemos perceber ao analisarmos as pesquisas acima, não existe uma conclusão globalmente aceita sobre a eficiência de interfaces tridimensionais. Enquanto que algumas pesquisas concluem que três dimensões podem de fato auxiliar usuários, outras descobrem que um número maior de dimensões pode prejudicar a eficiência dos usuários. Isto leva a crer que talvez sejam necessários métodos padronizados para a verificação da usabilidade de interfaces tridimensionais. Já existe uma enorme quantidade de tais métodos para interfaces bidimensionais [Ivory01a]. Porém, devemos levar em conta que, ao passo que é possível classificar a maioria das interfaces bidimensionais em dois grupos (WIMP e Web, conforme descrito no capítulo 2), as interfaces tridimensionais tendem a variar radicalmente em entre si. Isto sugere que, caso interfaces tridimensionais venham a ser agrupadas, seja necessário um número substancial de diferentes classificações que comportem os tipos já existentes de interfaces. 


\section{Capítulo 7}

\section{Considerações de projeto para interfaces 3D}

Durante o projeto de uma interface tridimensional, surge uma série de situações e problemas que são praticamente inexistentes em interfaces bidimensionais. Se por um lado interfaces tridimensionais podem de um certo modo oferecer mais opções ao projeto, dado o maior número de dimensões, o número de problemas que devem ser enfrentados também aumenta.

\subsection{Navegação}

Talvez seria possível argumentar que, como vivemos em um mundo tridimensional, seria mais natural que utilizássemos interfaces tridimensionais. Porém, já foi demonstrado que interfaces tridimensionais podem introduzir novas dificuldades para os usuários [Coc02a]. Esta seção irá analisar aspectos de navegação em interfaces bidimensionais e tridimensionais.

\subsubsection{Mapas Cognitivos}

Um problema logo fica aparente quando exploramos ambientes bidimensionais em hipermídia, como a Internet, por exemplo. O espaço não é completamente conhecido pelos usuários, que precisam então construir seus próprios mapas cognitivos. Isto pode ser feito usando, por exemplo, ferramentas de busca, que podem facilmente confundir o usuário [Jul97a]. 
Como vivemos em um ambiente tridimensional no mundo real, seria de se imaginar que seria mais fácil navegarmos em três dimensões em nossos computadores. Uma interface tridimensional poderia mais facilmente imitar o mundo real do que uma interface bidimensional. Isto ocorre porque uma interface tridimensional poderia, por exemplo, incluir mais facilmente componentes como marcos e caminhos, conforme analisado no capítulo 4. Isto implica que seria possível tirar vantagem da habilidade natural das pessoas para criar mapas cognitivos, o que facilitaria a navegação no espaço virtual [Dar93a, Cze00a]. Porém, quando falamos de realidade virtual não-imersiva, observamos que existe o problema de representar um mundo tridimensional através de equipamentos que apenas podem exibir imagens bidimensionais. Além disso, cada usuário tem habilidades espaciais diferentes, o que pode influenciar muito na utilização da interface. Se por um lado este problema não existe em interfaces bidimensionais, onde a navegação é bidimensional e logo tende a ser diferente, também não é possível utilizar eficientemente a habilidade espacial dos usuários em interfaces bidimensionais.

\subsubsection{Habilidade Espacial}

Um dos maiores problemas relacionados a interfaces gráficas tridimensionais é a maior liberdade de movimento proporcionada ao usuário [Boy96a]. Neste caso, o número de eixos pelos quais o usuário pode se movimentar no espaço tridimensional é maior do que em interfaces bidimensionais. Isto leva a uma maior possibilidade de o usuário se perder no ambiente virtual. Esta possibilidade de se perder aumenta ainda mais se considerarmos sistemas de realidade virtual não-imersiva, onde o monitor não é capaz de proporcionar ao usuário um campo de visão amplo o suficiente [Rud98a, Rud99a].

Como a habilidade espacial de um usuário pode afetar o modo como utiliza interfaces gráficas [Höok97a], é importante desenvolver métodos para desenvolver interfaces que possam ser usadas por um grande número de usuários independente da habilidade espacial de cada um. Por exemplo, sabe-se que, quando um usuário navega em um ambiente virtual, é prudente não permitir que o mesmo vire seu ângulo de visão mais de 60 graus por 
movimento [Rie01a]. Deste modo, a desorientação do usuário é minimizada e a ilusão do ambiente virtual é mantida mais efetivamente.

\subsubsection{Cinetose}

Cinetose é, basicamente, um conjunto de sintomas (náuseas, vômitos e tonturas), associados a alterações de movimentos vibratórios, oscilatórios ou rotatórios [Bee01a]. Foram observados sintomas similares a cinetose em usuários durante, e algumas vezes depois, do uso de um ambiente virtual tridimensional. Estudos preliminares com simuladores de carros indicaram que o conflito de auxílios visuais é a fonte do problema. Esta teoria do conflito de auxílios visuais foi descrita por Goldberg e Hiller [Gol95a], e ocorre quando existe uma ambigüidade entre sentidos diferentes ou até mesmo em um mesmo sentido. Acredita-se que os dois conflitos principais causadores do problema ocorrem entre o sentido da visão e o sentido vestibular, que controla o nosso equilíbrio e está localizado no ouvido interno no vestíbulo. Os testes que chegaram a esta conclusão foram realizados em dois tipos de simuladores de ambientes virtuais, aqueles de base fixa e aqueles de base móvel. Em um simulador de base fixa, o sentido da visão percebe movimento enquanto que o sentido vestibular não sente nada. Logo, um conflito ocorre entre os sentidos, o que pode causar enjôo e desorientação. Em um sistema de base móvel, o estímulo visual pode não corresponder exatamente aos movimentos registrados pelo sentido vestibular. Neste caso também ocorre um conflito.

Apesar de já existirem algumas soluções que reduzem um pouco a cinetose em alguns casos [Bee01a], este ainda é um tópico que deve ser estudado. 


\subsection{Interação}

Desde a concepção da metáfora do ambiente de trabalho bidimensional, foram criados certos padrões que são aceitos pela grande maioria dos usuários. Estes padrões referem-se a ícones, janelas, e outros componentes de interfaces gráficas que são amplamente utilizados e compreendidos. No campo de interfaces gráficas tridimensionais, ainda não existe padrão algum. Esta falta de padrão pode por algumas vezes levar a certos erros de projeto. Porém existem alguns paralelos que podem ser traçados entre elementos de interfaces bidimensionais e elementos tridimensionais que podem auxiliar no projeto destas interfaces.

\subsubsection{Atenção}

O projeto de uma interface deve permitir que os usuários focalizem sua atenção com um mínimo de sobrecarga cognitiva [Pre94a]. Também é importante manter a atenção do usuário, e recuperá-la caso ela seja perdida indevidamente. Em interfaces bidimensionais, existem certas técnicas de exibição de informação que permitem que isto seja feito, como, por exemplo, cores diferentes, texto piscante e auxílios aurais, como sons de alerta.

Para obter atenção do usuário, interfaces tridimensionais podem tomar vantagem do fato que diferenças em aparências visuais atraem a atenção do olho humano, como, por exemplo, cor, textura, sombras, tamanho, localização e movimento [Wis98a]. O problema aqui é que interfaces tridimensionais tendem a apresentar imagens mais complexas para o usuário, especialmente aquelas que procuram utilizar elementos de realidade virtual. Isto pode criar uma quantidade de cores e objetos na tela que atraem a atenção do usuário simultaneamente, o que pode prejudicar o uso da interface. Para que isto não ocorra, é necessário que não haja muitos objetos movimentando-se ao mesmo tempo. Além disso, 
deve-se evitar o uso excessivo de cores que, assim com em interfaces bidimensionais, podem confundir o usuário [Mar93a].

\subsubsection{Capacidades (affordances)}

O paradigma de manipulação direta causou o desenvolvimento de um certo tipo de linguagem visual em aplicativos. Começando desde a interface Star, desenvolvida pela Xerox em 1977, a metáfora do ambiente de trabalho (desktop) se estabeleceu como um certo padrão em varias plataformas diferentes, como Macintosh e Windows, por exemplo. Sendo assim, um número substancial de usuários adquiriu algum tipo de familiaridade com as capacidades de componentes de interfaces bidimensionais [Wis98a]. Essas propriedades fundamentais dos componentes que são percebidas pelos usuários são chamadas de capacidades [Nor98a]. Um usuário geralmente reconhece imediatamente certos elementos de interfaces, mesmo que sejam de sistemas diferentes. Um botão parece o mesmo tanto no Windows como no Macintosh, e mostra ao usuário que pode ser pressionado.

As metáforas em interfaces tridimensionais são menos desenvolvidas que aquelas de interfaces bidimensionais, o que geralmente obriga que projetos de interfaces tridimensionais desenvolvam novos paradigmas ou então adaptem e utilizem componentes de interfaces bidimensionais [Con92a]. Isto pode não ser ideal, uma vez que os novos paradigmas introduzidos são únicos a uma interface específica, e componentes projetados para ambientes bidimensionais podem perder sua eficiência se adaptados para funcionar em um sistema tridimensional. Isto levou alguns pesquisadores a uma tentativa de utilizar metáforas encontradas no mundo real em interfaces tridimensionais para melhor oferecer capacidades aos usuários. Por exemplo, um objeto que se parece com uma gaveta pode ser aberto. Isto supostamente facilitaria o uso da interface, uma vez que os usuários já estariam familiarizados com o uso destes objetos no mundo real. Porém, existem poucos estudos sobre o impacto específico destas metáforas em uma interface tridimensional. 


\section{Capítulo 8}

\section{Influência de elementos de realidade virtual}

O projeto e implementação de interfaces gráficas tridimensionais ainda é um campo da interação humano-computador que está na sua infância. Ainda falta muito para que uma interface tridimensional possa substituir a grande maioria das interfaces gráficas bidimensionais existentes atualmente. Conforme mostrado em capítulos anteriores, em particular no capítulo 6 , existe uma série de pesquisas atuais que preocupam-se em pesquisar e melhorar vários aspectos de interfaces tridimensionais. Neste capítulo descrevemos nossa contribuição para as pesquisas nesta área.

\subsection{Realidade virtual}

De todas as pesquisas sendo feitas na área de interfaces tridimensionais, praticamente nenhuma preocupou-se em determinar qual é a influência que elementos de realidade virtual não-imersiva podem ter em tais interfaces. Mais especificamente, não se sabe ao certo se tais elementos influenciam os usuários em um ambiente tridimensional da mesma maneira que os influenciam em ambientes bidimensionais. Em interfaces que utilizam realidade virtual imersiva, podemos observar que estes elementos podem, de fato, auxiliar os usuários em certos casos, conforme visto no capítulo 5. Porém, não se sabe até que ponto este elementos podem ser úteis quando aplicados a uma interface tridimensional não-imersiva, conforme explicado no capítulo 3 . Tendo isto em vista, projetamos e implementamos um pequeno protótipo de uma interface tridimensional. Esta interface tem duas partes: uma procura utilizar elementos de realidade virtual não-imersiva ao máximo (parte realista), ilustrada na figura 8.1, enquanto a outra utiliza apenas elementos abstratos (parte abstrata), mostrada na figura 8.2. Ambas as partes são ambientes tridimensionais. Esta interface será utilizada em um teste com vários usuários para que possamos 
determinar qual é de fato o impacto que certos elementos de realidade virtual podem ter em usuários de interfaces gráficas tridimensionais.

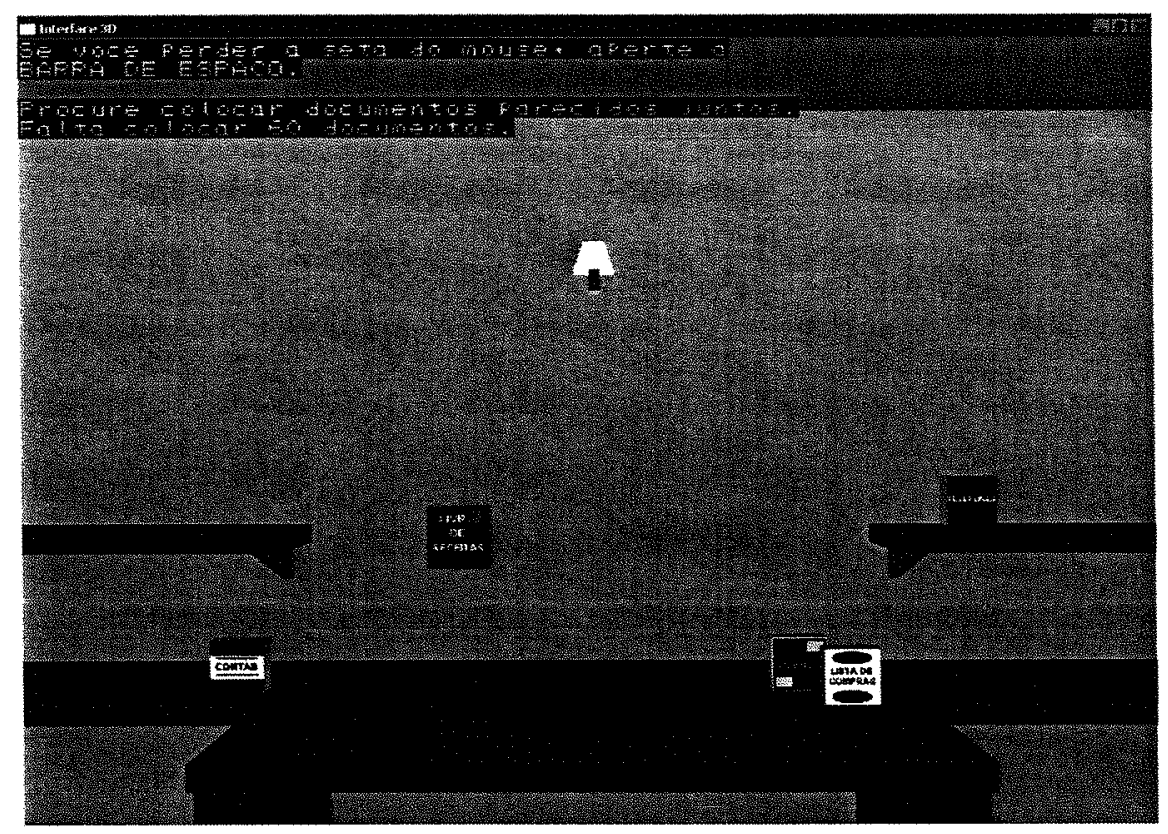

Figura 8.1 - Interface tridimensional - parte realista

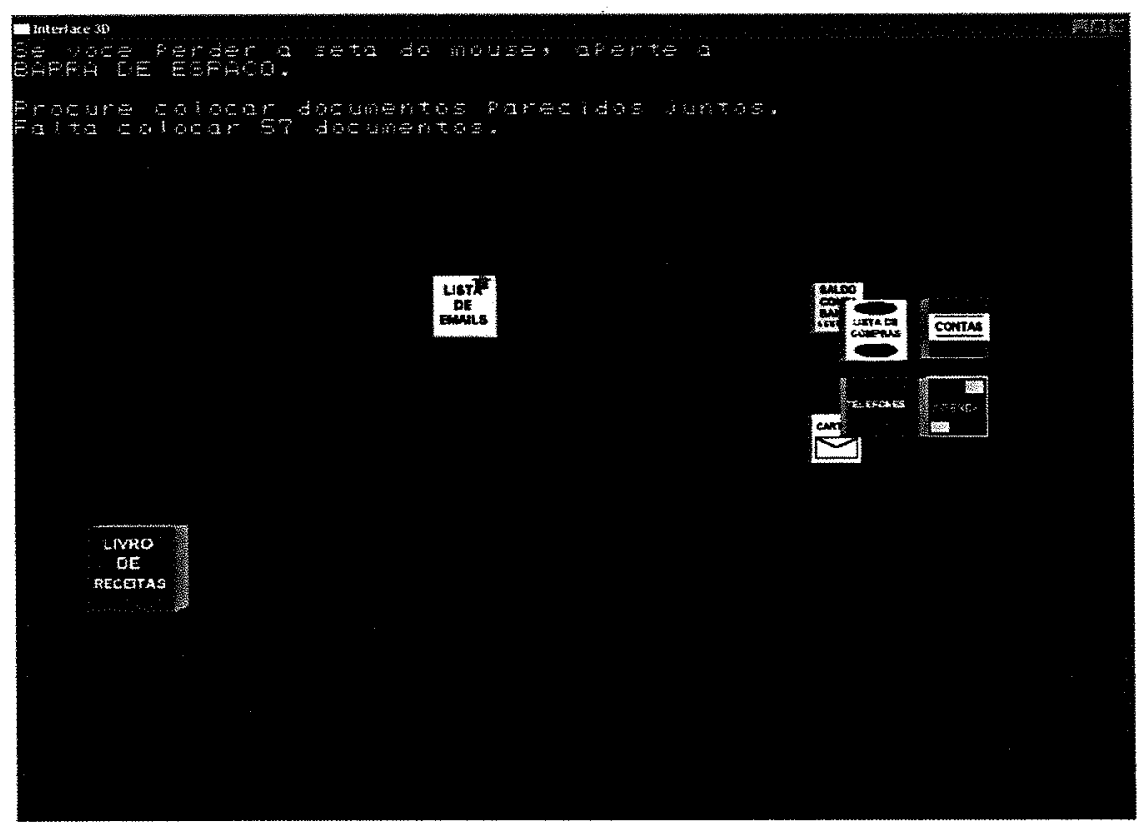

Figura 8.2 - Interface tridimensional - parte abstrata 


\subsection{Protótipo de uma interface tridimensional}

A interface tridimensional criadas por nós permite o gerenciamento de documentos em um ambiente tridimensional. Optamos por utilizar documentos genéricos, que representam arquivos comuns, como, por exemplo, "correio eletrônico" e "contas a pagar". Outros tipos de documentos poderiam ser usados, como imagens ou páginas retiradas da Internet.

Esta interface tridimensional foi projetada para executar em computadores pessoais. Não há a necessidade de equipamentos especiais adicionais. Desta forma, toda a interação fazse através do mouse; a interface é projetada de tal modo que o teclado não se faz necessário, apesar de poder ser utilizado, caso o usuário assim deseje. Existe uma única função no teclado que permite que o usuário recupere o ponteiro virtual, conforme será visto adiante.

Como o objetivo da interface não era criar um substituto para as interfaces atuais, o gerenciamento dos documentos foi apenas implementado em um nível básico. A interface permite que usuários organizem documentos em um espaço tridimensional virtual conforme a interface apresenta estes documentos para o usuário. O espaço virtual está inicialmente vazio, e a interface apresenta ao usuário um documento por vez, para que o usuário organize da maneira que melhor lhe convier. No ambiente abstrato, os documentos podem ser colocados em qualquer lugar do espaço tridimensional, não havendo restrições. Já no ambiente que procura simular o mundo real, existem várias restrições. Por exemplo, um documento apenas pára se colocado em uma superfície; se o usuário deixar um documento em outro lugar do espaço, este, através da "simulação de gravidade", cairá até encontrar uma superfície.

Ao contrário de interfaces tridimensionais anteriores [Rob98a, Rob00a], decidimos permitir que o usuário modifique o seu ponto de vista no mundo virtual. Isto significa que 
o usuário pode "olhar" para os lados no ambiente virtual. Sabe-se que, conforme a liberdade de movimento dos usuários em mundos virtuais aumenta, a probabilidade de que fiquem desorientados também aumenta [Coc02a]. Deste modo, nossa interface apenas permite a rotação do ponto de vista em um eixo, de modo que o usuário possa olhar para a esquerda e para a direita, mas não para cima e para baixo. Além disso, os usuários também não podem mudar a sua localização no mundo virtual. Isto limita a liberdade dos usuários, mas não é uma característica necessária, tendo em vista que todo o mundo virtual é facilmente alcançado pelo usuário a partir de uma única localização. Deste modo, evita-se muitos dos problemas relacionados à navegação em espaços virtuais tridimensionais, conforme aqueles descritos no capítulo 4 .

O usuário pode olhar para a esquerda ou direita encostando o ponteiro nos cantos esquerdo e direito da tela, respectivamente. Sabe-se que ângulos de rotação de até 60 graus podem ser muito eficientes em ambientes virtuais em simular o movimento de rotação da cabeça no mundo real. Na nossa interface, optamos por um ângulo de rotação de 45 graus. Isto significa que, quando o ponteiro toca um dos lados da tela, o ponto de vista virtual do usuário gira 45 graus para a esquerda ou direita. Este giro não é imediato, mas é feito através de uma pequena animação que vai modificando o ponto de vista progressivamente até que o ângulo de rotação de 45 graus seja atingido. Encostando o ponteiro novamente em um dos lados gira novamente o ponto de vista. A figura 8.3 demonstra o ambiente no ponto de vista inicial, e a figura 8.4 o mostra após uma rotação de 45 graus para a esquerda. Para evitar uma possível desorientação, o usuário pode apenas gira um máximo de 90 graus a partir do ponto inicial. Isto significa que o usuário não pode, por exemplo, "olhar para trás" no mundo virtual. Apesar disso, o usuário ainda tem espaço suficiente para organizar todos os documentos.

Os documentos são representados no espaço virtual através de objetos retangulares. A sua cor e o texto escrito na parte da frente de cada documento são as características através das quais os usuários devem identificá-los; o sistema não oferece nenhum outro auxílio ao 


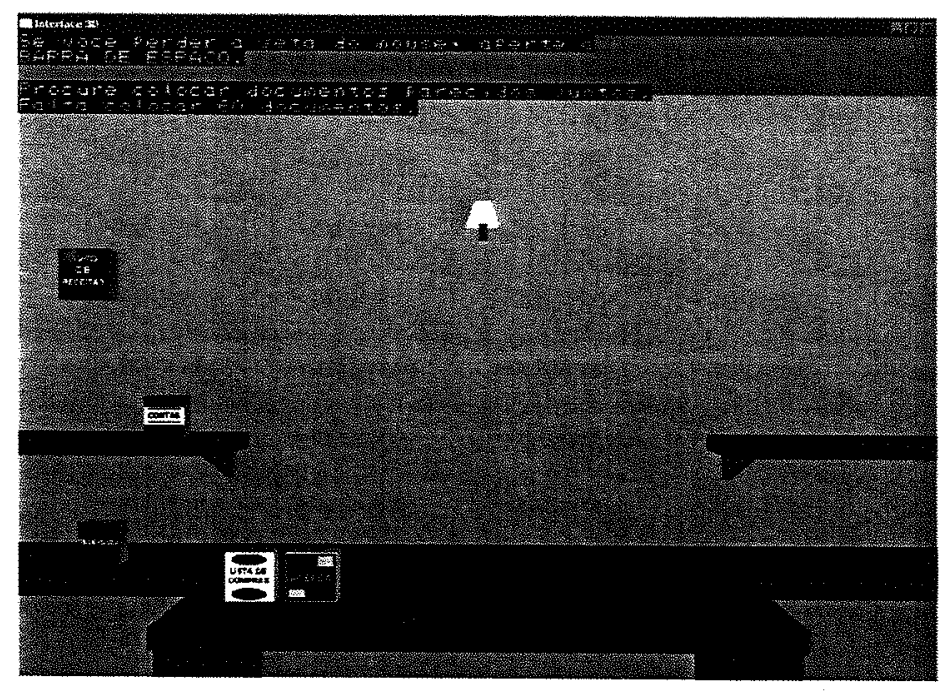

Figura 8.3 - Ponto de vista inicial

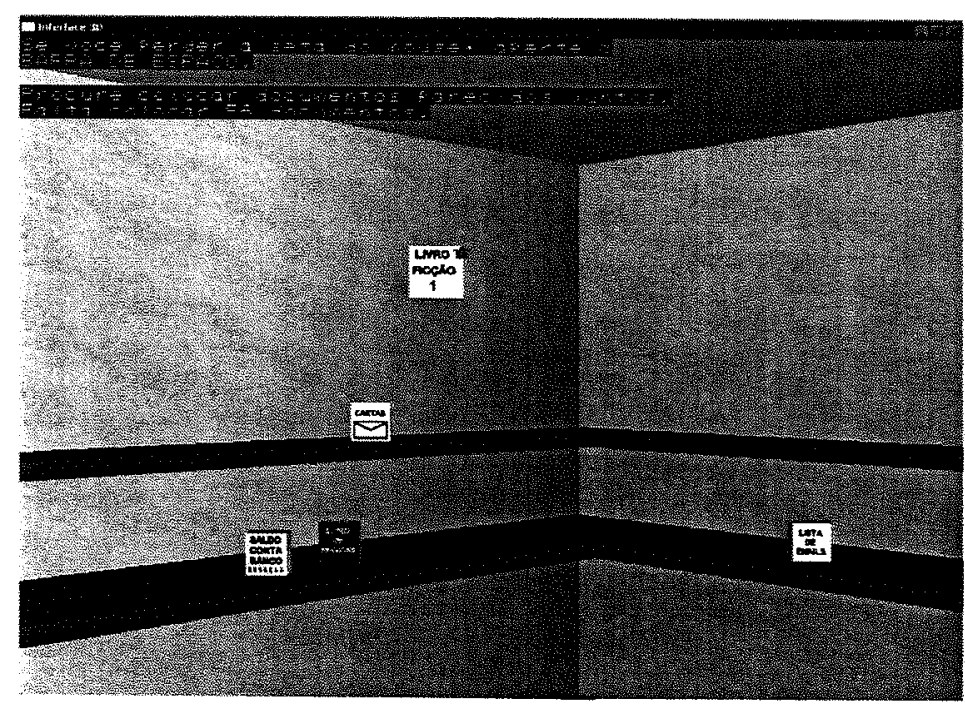

Figura 8.4 - Ponto de vista após rotação para a esquerda

usuário com relação à identificação destes documentos, e o sistema não permite que os arquivos sejam abertos ou seu conteúdo analisado. Para segurar um documento, basta que o usuário posicione o ponteiro à frente do mesmo, e então aperte o botão do mouse. $\mathrm{O}$ documento então segue o movimento do ponteiro, nos três eixos, até que o botão do mouse seja pressionado novamente. Neste ponto, o comportamento do documento será diferente dependendo de onde o usuário estiver. Caso esteja na parte abstrata, o documento fica 
exatamente onde o usuário o deixou. Já na parte realista, o documente irá cair até que encontre alguma superfície. Para manter a simplicidade de uso, os documentos param de cair mesmo que apenas uma pequena parte colida com alguma superfície, ou seja, o documento não se inclina e continua a cair, mas pára ali mesmo. Como a interface apenas permite que o usuário olhe para os lados, e não para baixo, foi implementado um sistema que recuperava todos os documentos que o usuário deixava cair no chão na parte realista da interface. Estes documentos recuperados reapareciam à frente do usuário com uma mensagem dizendo ao usuário que aquele documento tinha caído no chão. Este sistema se fez pouco necessário, pois notamos durante os teste que poucas vezes os usuários deixavam os documentos caírem no chão, e, geralmente quando o faziam, estavam ainda começando a se familiarizar com a interface.

\subsubsection{Alguns aspectos cognitivos}

Com a exceção do próprio ponteiro do mouse movimentado pelo usuário, e dos documentos caindo, não existe qualquer outro tipo de movimento na tela da interface. Mesmo que algum tipo de movimento pudesse ter auxiliado na implementação da fase realista, optamos por não coloca-los pois isto poderia atrair inadvertidamente a atenção do usuário. Conforme dito, documentos largados no ar, sem contato com alguma superfície, caem, e seu movimento pode atrair a atenção do usuário. Notamos durante os testes que a maioria dos usuários geralmente soltava os documentos perto das superfícies (na fase realista), e que os mesmos então apenas caíam uma pequena distância. Deste modo, seu período de movimento era curto e não contribuía para atrair inadvertidamente a atenção do usuário.

O uso de cores nos ambientes virtuais em si também foi limitado, na medida do possível. Os documento, por outro lado, tinham cores variadas. As texturas utilizadas para mostrar os nomes de cada documento tipicamente tinham um fundo de cor sólida, com o texto em si em outra cor que possibilitasse uma boa visualização. Em algumas destas texturas, 
alguns outros elementos gráficos foram utilizados. A figura 8.5 mostra alguns exemplos destas texturas utilizadas para mostrar os nomes dos documentos.

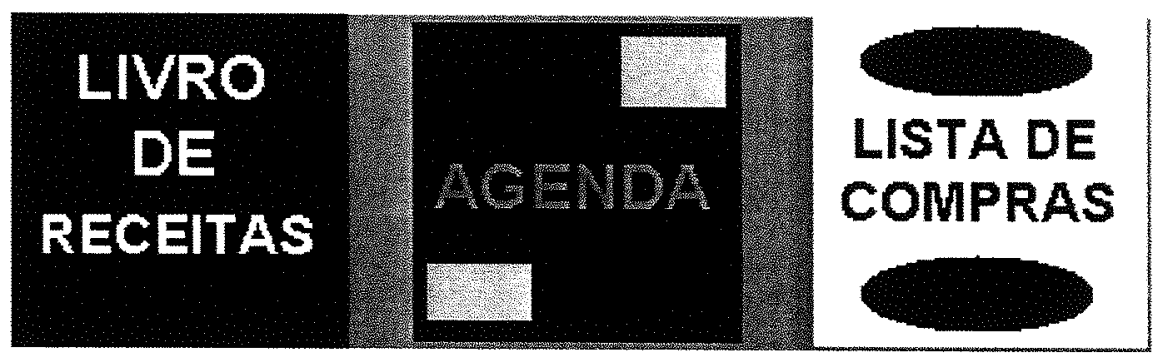

Figura 8.5 - Exemplos de texturas utilizadas nos documentos

\subsubsection{Implementação}

A interface executa em sistemas Win32 que tenham subsistemas gráficos compatíveis com o padrão OpenGL 1.1 e que sejam capazes de exibir uma resolução mínima de 800 por 600 pixels com profundidade de cor de 32 bits. O motivo desta profundidade de cores é o sistema de sombras, que faz uso de transparência para criar sombras mais realistas (caso o subsistema gráfico o permita). Todas as texturas utilizadas na interface têm dimensão de 128 pixels por 128 pixels com profundidade de cor de 24 bits, e são redimensionadas dinamicamente conforme necessário. Todo o sistema foi desenvolvido na linguagem $\mathrm{C}++$, utilizando o Microsoft Visual C++ 6.0 como ambiente de desenvolvimento. Com exceção das bibliotecas padrão do sistema Win32, todas as outras funções, como, por exemplo, detecção de colisão, foram escritas por nós.

Para criar a ilusão de tridimensionalidade, foram utilizados auxílios monoculares, como sombras, texturas, perspectiva linear e iluminação. Referências binoculares não foram utilizadas, pois o intuito era poder executar esta interface em computadores com equipamentos convencionais. Todo o texto da interface é escrito na parte superior da tela, com um fundo opaco. O texto sempre aparece no mesmo lugar do monitor, e acompanha o ponto de vista do usuário. As propriedades fundamentais de cada documento que 
procuramos passar ao usuários (capacidades) eram básicas: a única ação que podia ser realizar era pegar (ou soltar). Todos os documentos virtuais tinham o mesmo tamanho e eram manipulados da mesma maneira. A única diferença entre os documentos era o texto descritivo na parte da frente de cada documento.

\subsubsection{Movimento no ambiente virtual}

O usuário é representado do espaço virtual por uma seta que age como se fosse o ponteiro de um mouse convencional. Porém, o usuário pode movimentar a seta nos três eixos do espaço. Para isto, foi necessário criar um sistema que, idealmente, permitisse que o usuário utilizasse um dispositivo bidimensional, como o mouse, para mover a seta em três dimensões.

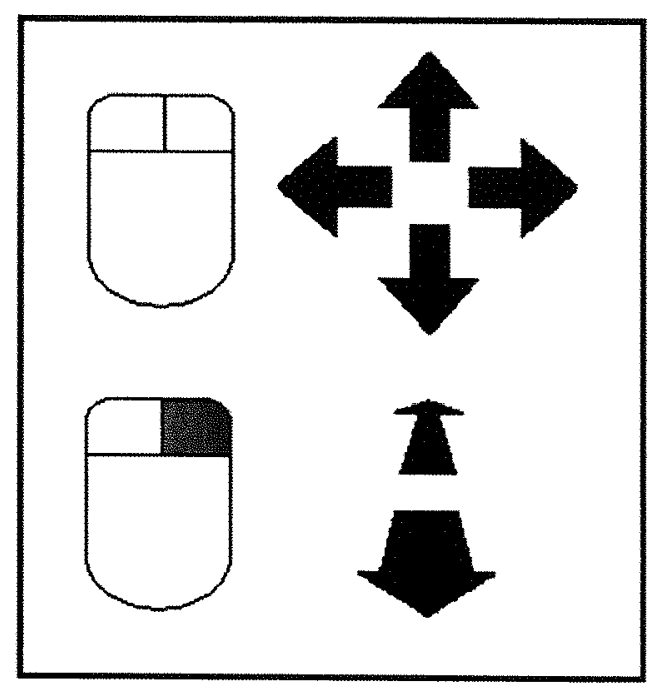

Figura 8.6 - Sistema de movimentação

O eixo de movimento da seta é determinado verificando-se se o usuário está pressionado o botão direito do mouse. Quando o botão direito não está pressionado, a seta é movimentada de maneira similar a uma interface gráfica bidimensional: o movimento do mouse causa com que a seta mova-se por um plano paralelo à tela do monitor. Quando o usuário mantém pressionado o botão direito, os movimentos do mouse causam com que a 
seta mova-se no plano perpendicular ao monitor, ou seja, "para frente e para trás". A figura 8.6 demonstra o funcionamento deste sistema. Desta maneira, o usuário consegue movimentar a seta para qualquer lugar do ambiente virtual, ao mesmo tempo que utiliza apenas um dispositivo bidimensional.

Apesar de o movimento ser relativamente simples nesta interface, ainda é possível que o usuário, por algum motivo, se perca no ambiente virtual. Mais especificamente, é possível que o usuário perca de vista a seta do mouse, sem saber onde a mesma está. Como o ambiente da interfce é tridimensional, pode acontecer a oclusão de objetos. Isto é, um objeto que estiver atrás de outro não pode ser visto diretamente pelo usuário. Como, na interface, todos os documentos têm o mesmo tamanho, e devido à organização do espaço, é muito difícil que um documento esteja completamente oculto por outro. Porém, a seta do mouse é significantemente menor, e um usuário poderia, ao se desorientar, eventualmente perder de vista a seta. A interface permite que se "recupere" uma seta perdida, bastando apenas ao usuário pressionar a barra de espaço no teclado. Durante todos os testes, este recurso foi utilizado apenas três vezes.

\subsubsection{Colisão}

Outro aspecto importante da interface é a colisão: o que acontece, por exemplo, quando o usuário está segurando um documento e o mesmo colide com algo. Em nossa interface, optamos por implementar colisão de modo limitado, por vários motivos.

A colisão entre documentos não existe. Isto significa que, se o usuário estiver segurando um documento e este colidir com outro documento, nada acontecerá. A princípio, isto pode parecer que prejudica o usuário, mas na realidade o que acontece é exatamente o oposto. Nos primeiros protótipos da interface, a colisão entre documentos existia. O que se constatou foi que, conforme o número de documentos na tela aumentava, a quantidade de colisões entre eles também aumentava. Isto acontecia principalmente quando o usuário tentava colocar um novo documento entre outros documentos similares que já estivessem 
pertos um dos outros. Os documentos colidiam entre si e o usuário não conseguia colocar o documento no lugar desejado, o que obrigava o usuário a colocar o documento em outro lugar e também causava um certo grau de frustração. Para evitar este tipo de problema, a colisão entre documentos foi retirada. Isto poderia causar um outro tipo de problema: um usuário poderia inadvertidamente colocar um documento "dentro de outro documento". Porém, mesmo com este tipo de colisão desativado, não notamos este tipo de problema durante os testes.

A colisão com outros objetos do mundo, como paredes e prateleiras, continuou ativa. A seta do mouse em si jamais colidia com nada; porém os documentos, apesar de não colidirem entre si, colidiam com os objetos do mundo. Na parte realista da interface, estes objetos com os quais os documentos podiam colidir consistiam das paredes da sala virtual, de uma mesa e de prateleiras. Sempre que o usuário estivesse segurando um documento, o mesmo podia colidir com os objetos acima. $\mathrm{Na}$ fase realista, isto ajudava a criar a ilusão do mundo real, uma vez que os usuários não conseguiam "atravessar" objetos sólidos com os documentos. Estes objetos também serviam de apoio para os documentos, pois na fase realista, conforme dito anteriormente, os documentos não podiam pairar no ar. Isto também não permitia que os usuários saíssem da área inicial da interface, pois as paredes, teto e chão agiam como limites. Na parte abstrata, os únicos objetos presentes que causavam colisão eram quatro planos que, apesar de não serem paredes, também agiam como tal impedindo que usuários pudessem, inadvertidamente, colocar documentos em alguma área de difícil alcance.

\subsubsection{Tutorial}

Outro objetivo desta interface tridimensional era avaliar a facilidade com a qual usuários poderiam aprender a utiliza-la por si sós, sem intervenção de outras pessoas. Sendo assim, foi preparado um tutorial interativo que ensinava, passo a passo, a utilização da interface. O tutorial também era realizado em um ambiente tridimensional virtual. Através de textos 
mostrados no monitor, os usuários aprendiam como funcionava a interface e quais instruções deviam seguir. Havia uma série de exercícios que cada usuário deveria completar para conseguir terminar o tutorial. Todos os usuários passaram pelo tutorial antes que pudessem começar o teste. Em nenhum momento do aprendizado foram auxiliados por outras pessoas.

O tutorial começava com conceitos básicos, bidimensionais, e progressivamente ia ensinando a utilização da interface tridimensional. Do ponto de vista da implementação, o tutorial era dividido em várias fases:

1. Esta primeira fase verificava se o usuário sabia utilizar o mouse para mover a seta em duas dimensões.

2. Esta fase, ainda em duas dimensões, ensinava o usuário como segurar objetos.

3. Aqui o usuário era ensinado o que poderia acontecer a um documento se ele fosse solto. Por exemplo, o usuário aprendia que, na parte realista da interface, documentos soltos no ar caem até colidir com alguma coisa.

4. Nesta fase, os usuários tinham o primeiro contato com três dimensões. Eles aprendiam a utilizar o botão direito do mouse para mexer a seta para "frente e para trás", conforme descrito na seção 8.2.3.

5. Os usuários então finalmente aprendiam que, ao encostar do lado esquerdo ou direito da tela, do monitor com a seta, poderiam girar o seu ponto de vista no mundo virtual.

Após o término destas cinco fases, o tutorial então terminava e os testes em si começavam.

\subsection{Aplicação do teste}

O objetivo do teste era verificar com que facilidade os usuários conseguiam, após passar pelo tutorial, organizar e encontrar documentos em cada uma das partes, abstrata e 
realista, da interface tridimensional. Com isso, seria possível observar que impacto o uso de elementos de realidade virtual têm no uso de uma interface gráfica tridimensional, ou se, de fato, têm algum impacto. Também foi avaliada a facilidade com a qual os usuários podiam, por si mesmos, aprender a utilizar a interface utilizando somente o tutorial, sem qualquer outro tipo de ajuda. Após o término do teste, cada usuário respondeu a um questionário, baseado na escala Likert, que fazia várias perguntas subjetivas, como por exemplo, qual parte da interface o usuário preferia.

Conforme dito anteriormente, a interface tinha, além do tutorial, duas partes: a parte realista e a parte abstrata. A parte realista era uma sala virtual, com paredes, uma mesa ao centro e prateleiras. As prateleiras estavam distribuídas ao longo de todas as paredes, o que proporcionava uma boa quantidade de espaço para organização dos documentos. De qualquer maneira, uma parte do questionário após o término do teste perguntava se o espaço virtual em cada uma das partes foi suficiente para organizar todos os documentos.

O teste foi feito com 30 alunos do curso de matemática, sendo que a familiaridade dos usuários com interfaces gráficas variava desde o nível básico até o nível avançado. Nenhum usuário indicou ter alguma experiência prévia com interfaces gráficas tridimensionais. Cada aluno realizava o teste em um computador, sendo um computador por pessoa. Os computadores utilizados tinham processador Athlon 1.2 gigahertz, com 64 megabytes de memória. Os subsistemas gráficos destes computadores eram todos compatíveis com o padrão OpenGL 1.1, e os testes foram executados na resolução de 800 por 600 pixels, com uma profundidade de cor de 32 bits. Os dispositivos de entrada, como mouse e teclado, eram padrão. Cada teste durou em média 20 minutos.

Após o término do tutorial, a interface escolhia, aleatoriamente, uma das duas fases e então a apresentava ao usuário. Em cada uma das partes, 60 documentos eram apresentados, um por vez, ao usuário, que os organizava no ambiente virtual da maneira que quisesse. Cada usuário era então requisitado a encontrar 10 documentos, um por vez. Não havia limite 
máximo de tempo, e não houve casos de usuários não conseguirem encontrar documentos. Após o término de uma parte, realista ou abstrata, a interface apresentava a outra parte para o usuário, e o processo recomeçava. Ao final do teste, os usuários respondiam a um questionário, dividido em três seções, com questões genéricas e questões pertinentes a parte realista e a parte abstrata da interface.

\subsubsection{Resultados}

A tabela 8.1 mostra a análise do tempo gasto pelos usuários no tutorial. Todos os usuários terminaram o tutorial sem nenhum auxílio por parte de outra pessoa. Os valores indicados na tabela estão em segundos.

\begin{tabular}{|c|c|}
\hline TUTORIAL & $\begin{array}{c}\text { Estatística } \\
\text { (segundos) }\end{array}$ \\
\hline Média & $134,6 \pm 12,4$ \\
\hline Mediana & 132,0 \\
\hline DP & 61,9 \\
\hline Mínimo & 51,0 \\
\hline Máximo & 265,0 \\
\hline
\end{tabular}

Tabela 8.1 - Análise do tempo gasto com o tutorial

Conforme indicado na tabela, nenhum usuário levou mais do que cinco minutos para completar o tutorial, o que sugere, a princípio, que o tutorial pode introduzir os conceitos básicos da interface de modo eficiente. Isto é confirmado pelo fato que não houve desistências durante os testes (todos os usuários completaram o teste). Este fato, junto com a observação dos usuários durantes os teste, indica que a interface não causou nenhum nível elevado de frustração ou outro sentimento que impedisse a execução do teste.

De fato, conforme será visto adiante, a grande maioria dos usuários respondeu ao final do teste, no questionário, que foi fácil seguir os passos do tutorial para aprender a utilizar a interface. 


\subsubsection{Organização dos documentos}

A tabela 8.2 mostra os resultados referentes à organização dos documentos. Classificamos a parte realista como sendo parte 1 , e a parte abstrata como parte 2 . Os valores referem-se ao tempo em segundos.

\begin{tabular}{|c|c|c|}
\hline & $\begin{array}{c}\text { Parte 1 } \\
\text { (segundos) }\end{array}$ & $\begin{array}{c}\text { Parte 2 } \\
\text { (segundos) }\end{array}$ \\
\hline Média & $610,0 \pm 44,8$ & $352,7 \pm 24,5$ \\
\hline Mediana & 537,0 & 337,0 \\
\hline DP & 224,0 & 122,5 \\
\hline Mínimo & 307,5 & 138,5 \\
\hline Máximo & 1054,0 & 697,0 \\
\hline
\end{tabular}

Tabela 8.2 - Análise do tempo utilizado para organizar documentos

Note que os tempos no ambiente abstrato (Parte 2) são claramente menores do que os da Parte 1. Não apenas a média e mediana foram menores, como também a variabilidade dos tempos (desvio-padrão e amplitude). Isto indica que os usuários tiveram consideravelmente mais dificuldade para organizar os documentos no ambiente realista.

$\mathrm{O}$ teste $\mathrm{t}$-pareado indicou que o tempo médio gasto na Parte 1 foi significativamente maior do que na Parte $2(\mathrm{P}<0,001)$; com 95\% de confiança, a diferença entre os tempos médios está entre 164,5 e 350,0 segundos. Aplicamos também o teste (não paramétrico) sinalizado de Wilcoxon que confirmou os resultados do teste $\mathrm{t}(\mathrm{P}<0,001)$. A figura 8.7 mostra o gráfico que descreve as diferenças entre as distribuições dos tempos de organização nas partes 1 e 2 . 


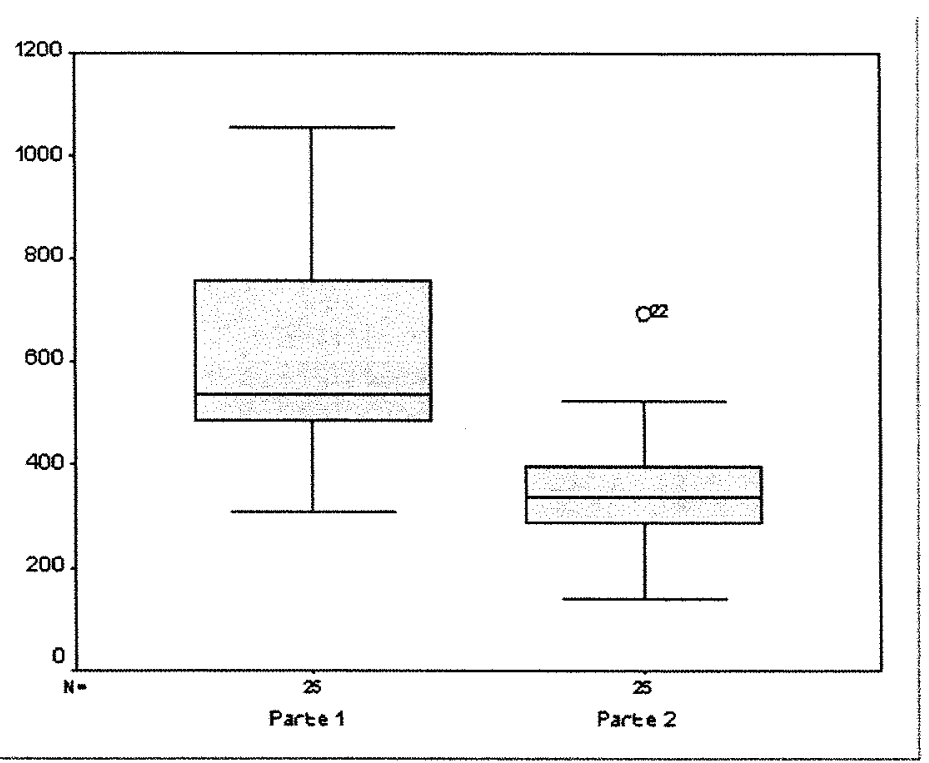

Figura 8.7 - Gráfico das diferenças entre as distribuições de tempos

Através da observação dos usuários durantes os testes, julgamos que o fator que mais causou dificuldades na parte realista foi a "simulação de gravidade", ou seja, o fato que, nesta parte, os documentos não podem pairar no ar. Isto contribuiu para diminuir a quantidade de espaço disponível para os usuários organizarem os documentos, uma vez que os mesmos apenas podiam ser colocados nas prateleiras ou na mesa do ambiente virtual. Conforme dito antes, os usuários tinham que recolocar aqueles documentos que deixassem cair no chão. Porém, essa perda de espaço não foi percebida pela maioria dos usuários, cuja maioria respondeu no questionário que tiveram espaço suficiente para organizar todos os documentos no ambiente realista.

\subsubsection{Localização dos documentos}

Após a organização dos 60 documentos no ambiente virtual, a interface escolhia aleatoriamente 10 documentos a pedia que o usuário os encontrasse, um por vez.

Analisando-se os tempos obtidos nesta fase do teste, existem duas observações excessivamente altas em relação às demais, ambas na parte 1: indivíduo 5 , documento 5 
(490,5 segundos) e indivíduo 18, documento 6 (386,5 segundos). Isto indica uma possível desorientação ou até mesmo uma organização falha dos usuários em questão. Estes dois usuários foram os únicos a utilizarem o sistema de "recuperação" do ponteiro virtual, conforme descrito na seção 8.2.3, o que sugerem que realmente podem ter ficado desorientados durante o teste. Por precaução, foram realizadas, nas seções 8.3.1.2.1 e 8.3.1.2.2, análises com e sem esses valores. Para testes de possíveis versões futuras da interface, seria prudente estabelecer um tempo máximo dentro do qual os usuários devem encontrar os documentos requisitados.

Para a análise dos tempos gastos na localização dos documentos, geramos duas medidas resumo: a primeira é o tempo médio gasto por pessoa e a segunda é a variância dos tempos gastos por pessoa. O objetivo da análise inferencial é verificar se há alteração nas médias dos tempos de organização e na variabilidade desses tempos entre as fases.

\subsection{Análise com todos os dados}

A Tabela 8.3 apresenta estatísticas descritivas das medidas.

\begin{tabular}{|c|c|c|c|}
\hline Indicador & & $\begin{array}{c}\text { Parte 1 } \\
\text { (segundos) }\end{array}$ & $\begin{array}{c}\text { Parte 2 } \\
\text { (segundos) }\end{array}$ \\
\hline \multirow{4}{*}{$\begin{array}{c}\text { Tempos } \\
\text { médios } \\
\text { individuais }\end{array}$} & Média & $13,9 \pm 3,3$ & $6,6 \pm 0,4$ \\
\cline { 2 - 4 } & Mediana & 9,2 & 6,2 \\
\cline { 2 - 4 } & D.P. & 16,3 & 2,1 \\
\cline { 2 - 4 } & Mínimo & 6,3 & 2,8 \\
\cline { 2 - 4 } & Máximo & 73,2 & 11,1 \\
\hline \multirow{4}{*}{$\begin{array}{c}\text { Variâncias } \\
\text { individuais }\end{array}$} & Média & $1641,6 \pm 1142,4$ & $11,7 \pm 2,3$ \\
\cline { 2 - 4 } & Mediana & 22,0 & 6,6 \\
\cline { 2 - 4 } & D.P. & 5712,0 & 11,5 \\
\cline { 2 - 4 } & Mínimo & 2,5 & 0,7 \\
\cline { 2 - 4 } & Máximo & 24963,1 & 38,8 \\
\hline
\end{tabular}

Tabela 8.3 - Estatísticas descritivas das medidas - todos os dados

$\mathrm{O}$ teste t-pareado indicou diferença significativa entre as médias $(\mathrm{P}=0,034)$ e inexistência de diferença significativa entre as variância médias $(\mathrm{P}=0,167)$. Um intervalo de $95 \%$ de 
confiança indicou que a média das diferenças entre as médias individuais está entre 0,6 e 14,1. Realizamos também um teste não paramétrico que é mais resistente quanto a presença de valores discrepantes. O teste sinalizado de Wilcoxon indicou diferença significativa entre as distribuições dos tempos médios individuais $(\mathrm{P}=0,001)$ e das variâncias individuais $(\mathrm{P}=0,005)$, sendo menor a variabilidade dos tempos na parte 2 . Tal fato sugere que, conforme explicado no capítulo 7 , a habilidade individual de cada usuário pode afetar sua eficiência no uso da interface. A parte abstrata, por apresentar menor variabilidade dos tempos, parece ser menos dependente da habilidade de cada usuário. Daí supõe-se que os elementos presentes na parte realista requeiram maior habilidade de cada usuário.

\subsection{Análise sem dados divergentes}

Analisamos aqui os mesmos dados, excluindo os indivíduos 5 e 18, que apresentaram dois tempos muito acima dos demais. A Tabela 8.4, apresenta estatísticas descritivas das medidas resumo.

\begin{tabular}{|c|c|c|c|}
\hline Indicador & & Fase 1 & Fase 2 \\
\hline \multirow{4}{*}{\begin{tabular}{c} 
Tempos $\begin{array}{c}\text { médios } \\
\text { individuais }\end{array}$ \\
\cline { 2 - 4 }
\end{tabular}} & Média & $12,1 \pm 2,8$ & $6,3 \pm 0,4$ \\
\cline { 2 - 4 } & Mediana & 8,9 & 6,1 \\
\cline { 2 - 4 } & D.P. & 13,5 & 1,9 \\
\cline { 2 - 4 } & Mínimo & 6,3 & 2,8 \\
\cline { 2 - 4 } & Máximo & 73,2 & 10,6 \\
\hline \multirow{4}{*}{$\begin{array}{c}\text { Variâncias } \\
\text { individuais }\end{array}$} & Média & $1124,0 \pm 1083,7$ & $10,5 \pm 2,3$ \\
\cline { 2 - 4 } & Mediana & 19,5 & 6,0 \\
\cline { 2 - 4 } & D.P. & 5197,1 & 11,1 \\
\cline { 2 - 4 } & Mínimo & 2,5 & 0,7 \\
\cline { 2 - 4 } & Máximo & 24963,1 & 38,8 \\
\hline
\end{tabular}

Tabela 8.4 - Estatísticas descritivas das medidas - sem dados divergentes

Através do teste t-pareado identificou-se diferença significativa entre as médias $(\mathrm{P}=0,059)$ e inexistência de diferença significava entre as variâncias médias $(\mathrm{P}=0,315)$. Um intervalo de $90 \%$ de confiança indicou que a média das diferenças entre as médias individuais está 
entre 0,8 e 10,8. O teste não paramétrico sinalizado de Wilcoxon indicou diferença significativa entre as distribuições dos tempos médios individuais $(\mathrm{P}=0,001)$ e das variâncias individuais $(\mathrm{P}=0,016)$, sendo menor a variabilidade dos tempos na parte 2 .

\subsubsection{Questionário}

Após a conclusão dos testes, cada usuário respondeu a um questionário contendo perguntas relativas à interface, tanto a parte realista e a parte abstrata. O objetivo deste questionário era avaliar o grau de satisfação de cada usuário, assim como obter respostas a perguntas subjetivas que a análise estatística dos dados não poderia fornecer. Cada pergunta foi elaborada de acordo com a escala Likert. Esta escala consiste em um conjunto de itens apresentados em forma de afirmações, ou juízos, ante os quais se pede aos usuários que externem suas reações, escolhendo um dentre cinco (no caso do nosso questionário) pontos de uma escala.

Para cada questão, deve-se definir qual será a atitude do usuário a ser medida. Feito isto, escrevemos uma afirmaão, com a qual o usuário poderá ou não concordar. Segue abaixo um exemplo de uma pergunta assim como constava no questionário; o objeto de atitude a ser medido era a facilidade de lidar com um pequeno número de documentos no ambiente virtual proporcionado pela interface.

Afirmação: Achei a interface eficiente para lidar com pequenos números de documentos.

(5) Concordo totalmente

(4) Concordo

(3) Nem concordo, nem discordo

(2) Discordo

(1) Discordo totalmente 
O usuário deveria escolher uma das alternativas, de 1 a 5, na escala acima.

O questionário tinha 12 perguntas, divididas em três partes. A primeira parte (questões 1 a 4) era genérica, contendo perguntas relativas à toda a interface. A segunda e terceiras partes tinham perguntas idênticas, com a diferença que as perguntas da segunda parte (questõea 5 a 8) eram referentes a parte realista e as perguntas da terceira fase (questões 9 a 12) eram referentes a fase abstrata. Ao final, uma última questão perguntava ao usuário qual das duas partes da interface seria sua favorita, caso tivesse que escolher apenas uma para manipular documentos. Seguem abaixo, na tabela 8.5 , as afirmações contidas em cada questão no questionário. A tabela 8.6 mostra o número de respostas que cada opção recebeu em cada pergunta.

\begin{tabular}{|c|l|}
\hline Questão & \multicolumn{1}{|c|}{ Afirmação } \\
\hline 1 & Foi fácil aprender com o tutorial. \\
\hline 2 & Tive dificuldade para movimentar o ponteiro em três dimensões. \\
\hline 3 & Achei a interface eficiente para lidar com pequenos números de documentos. \\
\hline 4 & $\begin{array}{l}\text { Acho que a interface perderia a eficiência se o número de documentos fosse } \\
\text { aumentado. }\end{array}$ \\
\hline 5 e 9 & Foi fácil organizar os documentos. \\
\hline 6 e 10 & Tive facilidade para encontrar os documentos pedidos. \\
\hline 7 e 11 & Tive facilidade para movimentar o ponteiro pela sala. \\
\hline 8 e 12 & Tinha espaço suficiente para organizar todos os documentos. \\
\hline 13 & $\begin{array}{l}\text { Se você tivesse que escolher um dos dois ambientes para trabalhar com } \\
\text { documentos, qual escolheria? }\end{array}$ \\
\hline
\end{tabular}

Tabela 8.5 - Afirmações das questões do questionário 


\begin{tabular}{|c|c|c|c|c|c|} 
& $\begin{array}{c}\text { Concordo } \\
\text { plenamente }\end{array}$ & Concordo & Indiferente & Discordo & $\begin{array}{c}\text { Discordo } \\
\text { plenamente }\end{array}$ \\
\hline Pergunta 1 & 20 & 4 & 0 & 1 & 0 \\
\hline Pergunta 2 & 2 & 5 & 5 & 2 & 11 \\
\hline Pergunta 3 & 10 & 8 & 6 & 1 & 0 \\
\hline Pergunta 4 & 15 & 3 & 4 & 1 & 2 \\
\hline Pergunta 5 & 10 & 4 & 4 & 3 & 4 \\
\hline Pergunta 6 & 15 & 3 & 3 & 1 & 3 \\
\hline Pergunta 7 & 7 & 6 & 3 & 1 & 8 \\
\hline Pergunta 8 & 23 & 0 & 0 & 1 & 1 \\
\hline Pergunta 9 & 21 & 2 & 1 & 1 & 0 \\
\hline Pergunta 10 & 21 & 1 & 1 & 0 & 2 \\
\hline Pergunta 11 & 3 & 4 & 2 & 4 & 12 \\
\hline Pergunta 12 & 21 & 1 & 3 & 0 & 0 \\
\hline $\begin{array}{l}\text { Texto em azul: perguntas relativas à parte 1 (realista) } \\
\text { Texto em verde: perguntas relativas à parte 2 (abstrata) }\end{array}$ &
\end{tabular}

Tabela 8.6 - Respostas de cada opção do questionário

A análise do resultado do questionário nos permite fazer algumas observações. Primeiramente, a interface claramente era fácil de ser aprendida. Apenas um único usuário sentiu dificuldades para utilizar o tutorial para aprender os conceitos básicos da interface. A princípio, poderíamos concluir que todos os outros 24 usuários possuíam boa habilidade espacial para lidar com elementos tridimensionais. Porém, a análise estatística dos testes em si, feita na seção 8.1, mostra que isso não é verdade e, de fato, as habilidades variam bastante entre cada usuário. Conclui-se, então, que, independente da habilidade de cada usuário, o tutorial foi eficiente e conseguiu ensinar os usuários a utilizarem, ainda que de modo básico, uma interface que jamais tinham visto antes. Isto também sugere que a interface poderia apresentar uma boa aprendibilidade.

A pergunta 2 refere-se à movimentação do ponteiro virtual, conforme descrito na seção 8.2.3. Sete pessoas, ou $28 \%$ dos usuários testados, manifestaram alguma dificuldade para movimentar o ponteiro em três dimensões. Apesar de minoria, isto sugere que o sistema de movimentação certamente pode ser melhorado, sendo este um possível objetivo para 
pesquisas futuras. Porém, esta dificuldade encontrada por alguns usuários não era de todo inesperada, uma vez que, conforme discutido em capítulos anteriores, ainda não existe um método ideal para utilizar movimentos de um dispositivo bidimensional para realizar movimentos tridimensionais. Além disso, apesar das dificuldades encontradas, todos os usuários conseguiram completar o teste, o que indica que o sistema de movimentação da interface cumpriu sua meta, ainda que parcialmente. Com relação à movimentação em cada ambiente, conforme respostas das questões 7 e 11, podemos observar que os usuários apresentaram muito mais dificuldade para movimentar-se no ambiente realista. Nove usuários, $36 \%$ do total, indicaram alguma dificuldade ao movimentar-se pelo ambiente realista, enquanto que apenas 2 usuários, $8 \%$ do total, indicaram dificuldade para movimentar-se no ambiente abstrato. Na realidade, o método de movimentação em ambas as partes era o mesmo. Isto nos leva a crer que outros fatores, como por exemplo, o espaço disponível para os documentos, afetou a movimentação dos usuários de alguma maneira.

Ainda analisando a tabela 8.6, nas questões 3 e 4, percebemos que a grande maioria dos usuários achou o espaço virtual suficiente para organizar 60 documentos, porém também indicaram que este mesmo espaço não seria suficiente caso o número de documentos aumentasse. As respostas das questões 8 e 12 mostram que os usuários têm uma pequena preferência pelo espaço disponível na parte abstrata. De fato, conforme discutido anteriormente, o espaço disponível para documentos na parte abstrata é maior do que aquele na parte realista. Mesmo assim, apenas dois usuários, ou $8 \%$ dos usuários testados, indicaram que o espaço na parte realista não era suficiente.

Com relação à organização dos documentos, podemos analisar as respostas dadas as questões 5 e 9, e concluir que os usuários acharam muito mais fácil organizar documentos na fase abstrata. Apenas um usuário indicou dificuldade para organizar documentos nesta fase, ao passo que 7 usuários, ou $28 \%$ do total, indicaram ter tido dificuldade para organizar documentos na parte realista. Isto faz algum sentido, uma vez que, conforme dito, o espaço disponível para documentos nesta parte era menor, e o usuários ainda tinham 
que lidar com a "simulação de gravidade", ou seja, existiam mais restrições na fase realista. Estas restrições causaram dificuldades a alguns usuários, conforme mostram as respostas das questões 5 e 9 .

As questões 6 e 10 referiam-se à facilidade com a qual os usuários puderam encontrar os documentos em ambas as partes. Encontrar um documento significava apenas segurá-lo com o ponteiro virtual, sistema que era idêntico em ambas as partes da interface. Conforme podemos observar na tabela 8.6 , os usuários demonstraram mais facilidade para encontrar documentos na fase abstrata. Como o método para encontrar documentos era igual nas duas partes, a organização dos documentos nas duas fases foi provavelmente o fator que mais pode ter influenciado as respostas destas duas questões. Como havia mais espaço disponível na parte abstrata, é possível que os usuários puderam organizar seus documentos de maneira mais eficiente, o que, por sua vez, permitiu que os encontrassem mais rapidamente.

A princípio, uma análise das respostas obtidas na tabela 8.6 nos leva a crer que os usuários prefeririam, quase que na sua maioria, a parte abstrata. Porém, as respostas obtidas para a questão 13 indicam que isto não é verdade. Aproximadamente um terço dos usuários (36\% do total) demonstraram preferência pela parte realista da interface, apesar desta parte ser claramente menos eficiente de acordo com a análise estatística. Uma possível explicação para esta preferência é o fato de a parte realista ter uma aparência melhor do ponto de vista dos usuários. Conforme podemos observar nas figuras 8.1 e 8.2 , a parte abstrata da interface possui um número mínimo de cores (se ignorarmos os documentos em si), além de não possuir nenhum outro objeto no espaço virtual. Isto indica que a aparência visual pode influenciar em muito a opinião de usuários, ainda que esta mesma aparência contribua para diminuir a eficiência da interface, como é o caso da parte realista. Uma possível melhora a ser contemplada em futuras versões da interface seria a melhora da aparência visual da parte abstrata, observando se isto de fato aumentar a preferência dos usuários por esta parte. 


\section{Capítulo 9}

\section{Conclusão}

Este trabalho tinha dois objetivos principais: fazer uma análise das interfaces gráficas tridimensionais em uso atualmente e observar o impacto que elementos de realidade virtual podem ter no uso deste tipo de interface.

Em nossa análise das interfaces tridimensionais, mostramos que este tipo de interface pode, de fato, proporcionar métodos mais convenientes ou eficientes de utilizar sistemas de computadores. Hoje em dia, este tipo de interface é utilizado em sistemas de diversas áreas, como, por exemplo, sistemas de visualização de informação, CAD, entretenimento e simulação. Acredita-se que interfaces tridimensionais fazem uso das habilidades dos usuários de criarem mapas cognitivos em três dimensões e que também podem, dentro de certos limites, aproveitar certas habilidades que os usuários já adquiririam no seu dia-a-dia. Porém, vale frisar que isto ainda não foi completamente comprovado. A própria eficiência deste tipo de interface ainda não pode ser comprovada e, conforme mencionamos, diferentes trabalhos de pesquisa chegam a diferentes conclusões sobre interfaces tridimensionais: enquanto uns consideram seu uso vantajoso, outros concluem que não há vantagens em utilizá-las. Isto, provavelmente, se deve ao fato de existirem poucos métodos através dos quais pode-se analisar a usabilidade de interfaces tridimensionais, enquanto existem centenas de métodos possíveis para se analisar um interface bidimensional [Ivory01a].

Além de serem relativamente novas no campo de interação humano-computador, as interfaces tridimensionais ainda não possuem um paradigma de desenvolvimento que permita que elementos comuns sejam utilizados durante seu projeto. Enquanto que em interfaces bidimensionais temos elementos como janelas e botões, por exemplo, não existe 
praticamente nada que possa ser considerado padrão quando falamos de interfaces tridimensionais. Além deste fato não facilitar a criação de métodos de análise, conforme mencionado acima, isto também acaba por prejudicar os usuários, pois os componentes de cada interface podem ser radicalmente diferentes. Isto significa que conceitos que um usuário aprendeu em uma interface tridimensional podem não ser aplicados em outra interface tridimensional, devido à diferença de seus componentes. Já em interfaces bidimensionais, o usuário pode, por exemplo, aprender que um botão pode ser pressionado, e então aplicar este conhecimento em muitas outras interfaces bidimensionais.

Este falta de padrão acaba por levar projetistas de interfaces tridimensionais a criarem sistemas híbridos. De fato, a maioria das interfaces gráficas tridimensionais hoje em dia utiliza alguns componentes de interfaces bidimensionais. Interfaces que conseguem evitar o uso destes componentes bidimensionais são raras. Em nosso protótipo desenvolvido durante este trabalho, conseguimos evitar o uso de elementos bidimensionais. Porém, isto provavelmente foi possível devido ao fato de a interface em si não ser muito complexa. Acreditamos que o uso de elementos bidimensionais seria inevitável caso um número maior de funções fosse adicionado à interface.

Apesar de interfaces gráficas tridimensionais serem já serem utilizadas em diversos campos, conforme mencionado, acreditamos que ainda não são capazes de substituir completamente as interfaces bidimensionais. Pesquisas recentes procuraram utilizar elementos tridimensionais para criar protótipos que eventualmente poderiam substituir a grande maioria das interfaces gráficas em uso em computadores pessoais, conforme mostrado no capítulo 6. Porém, ainda não se atingiu um grau de desenvolvimento necessário para que isto seja possível.

Neste trabalho, também implementamos um protótipo de interface tridimensional cujo objetivo era analisar o impacto que elementos de realidade virtual podem ter no uso deste tipo de interface. A interface implementada possui duas partes, uma realista, que utiliza 
elementos de realidade virtual, e outra abstrata, que não utiliza tais elementos. Através do teste com usuários, mostramos que estes elementos de realidade virtual podem na maioria das vezes reduzir a eficiência dos usuários. Por outro lado, estes mesmos elementos contribuíram para que aproximadamente um terço dos usuários testados indicassem preferência pela parte realista da interface. Em trabalhos futuros, seria interessante descobrir quais elementos da parte realista contribuíram para aumentar a preferência dos usuários, e então integrá-los a parte abstrata da interface. Deste modo, seria possível obter uma maior preferência pela parte abstrata, sem a perda de eficiência observada na parte realista. 


\section{Referências bibliográficas}

[And94a] Andrews, K. Spatial Metaphors for Information Systems, ECHT94 Workshop on Spatial Metaphors, 1994.

[Bee01a] Been-Lirn, B., Parker, D. e Furness, T. An "independent visual background" reduced balance disturbance envoked by visual scene motion: implication for alleviating simulator sickness. Proceedings of the SIGCHI conference on Human factors in computing systems, 2001.

[Bow00a] Bowman D. et al. The Art and Science of 3D Interaction Course Notes. IEEE Virtual Reality '2000, New Brunswick, USA, March 18, 2000.

[Boy96a] Boyd, C., e Darken, R. Psychological issues of virtual environment interfaces - a CHI 96 Workshop. SIGCHI Bulletin Vol. 28 nr. 4, 1996.

[Bro96a] Broll, W. VRML and the Web: A Basis for Multi- User Virtual Environments on the Internet. Proceedings of WebNet96, pp. 51-56, 1996.

[Bry91a] Bryson, S., e Levit, C. The Virtual Windtunnel: an Environment for the Exploration of Three-Dimensional Unsteady Fluid Flows". Proceedings of IEEE Visualisation '91, 1991.

[Bry96a] S. Bryson. Approaches to the Successful Design and Implementation of VR Applications. World Wide Web:

http://people.nas.nasa.gov/ bryson/papers/application.design.ps, 1996.

[Car91a] Card, S. K., Mackinlay J. D., and Robertson G. The Information Visualizer: An Information Workspace. ACM Conference on Human Factors in Computing Systems (CHI'91), pp 181-188, ACM Press, 1991.

[Car96a] Card, S. K., Robertson, G., and York, W. The WebBook and the WebForager: An Information Workspace for the World-Wide Web. Proceedings of CHI '96 Humans Factors in Computing Systems, pp 111-117, ACM Press, 1996.

[Che98a] Chen, C., e Czerwinski, M. Spatial Ability and Visual Navigation: An Empirical Study. Department of Information Systems and Computing, Brunel University, 1998.

[Coc02a] Cockburn, A., and McKenzie, B. Evaluating the Effectiveness of Spatial Memory in 2D and 3D Physical and Virtual Environments. Proceedings of CHI 2002, April 2002, pp. 203-210, ACM Press, 2002. 
[Coc01a] Cockburn, A., and McKenzie, B. 3D or Not 3D? Evaluating the Effect of the Third Dimension in a Document Management System. Proceedings of CHI '2001, April 2001, pp. 434-441, ACM Press, 2001.

[Con92a] Conner, D., Snibbe, S., Herndon, K., Robbins, D., Dam, A. Three Dimensional Widgets. Computer Graphics, Proceedings of the 1992 Symposium on Interactive $3 D$ Graphics, ACM SIGGRAPH, 1992.

[Coo97a] Coomans, M., Timmermans, H. Towards a Taxonomy of Virtual Reality User Interfaces. Proceedings of the International Conference on Information Visualisation (IV97), London, 1997.

[Cre03a] Creative Labs. EAX 3.0 SDK, http://developer.creative.com

[Cze00a] Czerwinski, M., Dantzich, M., Robertson, G., and Hoffman, H. The Contribution of Thumbnail Image, Mouse-over Text and Spatial Location Memory to Web Page Retrieval in 3D. Human-Computer Interaction-Proceedings of Interact '99, Edinburgh, Scotland, IOS press, pp. 163-170, 2000.

[Dar93a] Darken, R., and Sibert, J. A Toolset for Navigation in Virtual Environments. Proceedings of ACM User Interface Software \& Technology, 1993.

[Dar01a] Darken, R., and Peterson, B. Spatial Orientation, Wayfinding, and Representation. Handbook of Virtual Environment Technology, Stanney, K. Ed., 2001.

[Ded97a] Dedula, W. About Virtual Reality and Its Use in the Mobile Aeronautics Education Laboratory. http://www.grc.nasa.gov/WWW/MAELVRSTATION/news_info/vr_essay.html

[Dix98a] Dix, A., Finlay, J., Abowd, G., and Beale, R., Human-Computer Interaction, Prentice-Hall, 1998.

[Dijk03a] Dijk, B., Akker, R., e Zwiers, J. Navigation Assistance in Virtual Worlds. Informing Science Journal, Volume 6. 2003.

[Emb03a] Embraer: Centro de Realidade Virtual (CRV).

http://www.embraer.com.br/portugues/content/empresa/tecnologia/default.asp

[Fei93a] Feiner, S., MacIntyre, B., Haupt, M., and Solomon, E. Windows on the world: 2D windows for 3D augmented reality. Proceedings of UIST '93 (ACM Symposium on User Interface Software and Technology), Atlanta, GA, November 3-5, 1993, 145-155, 1993. 
[Foley92a] J. Foley, A.Dam, S. Feiner, e J. Hughes.Computer Graphics: Principles and Practice. Washington, DC: Addison-Wesley, 1992.

[Fun93a] Funkhouser, T, e Sequin, C. Adaptive Display Algorithms for Interactive Frame Rates During Visualization of Complex Virtual Environments. Computer Graphics (SIGGRAPH `93), August, 1993, p. 247-254.

[Gol95a] Goldberg, S., e Hiller, J. Simulator Sickness in Virtual Environments. Technical Report 1027, US Army Research Institute for the Behavioral and Social Sciences, 1995.

[Hag93a] Hagsand, e Carlsson. DIVE - A Platform for Multi-User Virtual Environments, Computers and Graphics 17(6), 1993

[Hewett01a] Hewett et al. ACM SIGCHI Curricula for Human-Computer Interaction. World Wide Web: http: //sigchi.org/cdg/cdg2.html, 2001.

[Höök97a] Höök, K., e Dahlbäck, N. Designing navigational aids for individuals. CHI 97 Workshop on Navigation in Electronic Worlds, 1997.

[Hun99a] Hunt, E., and Waller, D. Orientation and Wayfinding: A Review. World Wide Web, 1999.

http: //depts.washington. edu/huntlab/vr/pubs/huntreview.pdf

[Ivory01a] M. Ivory, e M. Hearst. The State of the Art in Automating Usability Evaluation of User Interfaces. ACM Computing Surveys, Vol. 33, No. 4, pp. 470-516. ACM Press, 2001.

[Jansen98a] B. Jansen. The Graphical User Interface: An Introduction. SIGCHI Bulletin. 30(2), 22-26. 1998.

[Jul97a] Jul, S., e Furnas, G. Navigation in Electronic Worlds: A CHI 97 Workshop. SIGCHI Bulletin 29 nr. 4, 1997.

[Mar93a] Marcus, A. SIGGRAPH 93 tutorial notes: Graphic Design for User Interfaces. 1993.

[Mansson98a] Mansson, J. Stereovision: A Model of Human Stereopsis. Lund University Cognitive Studies, 1998.

[Mullet95a] Mullet, K, Schiano, D., Robertson, G, Tversky, B. 3D or Not 3D: "More is Better" or "Less is More"? Proceedings of CHI '95, 1995. 
[Nas03a] NASA Ames Research Center: Vertical Motion Flight Simulation Laboratory. http://www.simlabs.arc.nasa.gov/vms/vms.html

[Nash00a] Nash, E., Edwards, G., Barfield, W. A review of presence and performance in virtual environments. International Journal of Human-Computer Interaction vol. 12, $p$. 41. 2000.

[Nor98a] Norman, D. The Design of Everyday Things. DoubleDay, 1998.

[Joh00a] St. John, M., Oonk, H., and Cowen, M. Using Two-Dimensional and Perspective Views of Terrain. SPAWAR Systems Center Technical Report Number 1815, 2000. (www.nosc.mil/sti/publications/pubs/tr/1815)

[Pet98a] Peterson, B., Wells, M., Furness III, T., and Hunt, E. The Effects of the Interface on Navigation in Virtual Environments. Human Factors and Ergonomics Society 1998 Annual Meeting, 1998.

[Pre94a] Preece, J, Rogers, Y., Sharp, H., Benyon, D, e Carey, T. Human-Computer Interaction. Addison-Wesley Publishing Company, 1994.

[Puk97a] Puk, R., Carson, G., e Carey, R. The Development of the VRML 97 International Standard. http://www.vrml.org/about/vrml_plb.html

[Rie01a] Riecke, B.E., von der Heyde, M. and Bülthoff, H.H. How do we know where we are? Contribution and interaction of visual and vestibular cues for spatial updating in real and virtual environments. TWK 2001. Beiträge zur 4. Tübinger Wahrnehmungskonferenz, 146. (Eds.) H.H. Bülthoff, K.R. Gegenfurtner, H.A. Mallot, R. Ulrich, Knirsch-Verlag, Kirchentellinsfurt, Germany, 2001.

[Ris00a] Risden, K., Czerwinski, M., Munzner, T., and Cook, D. An Initial Examination of Ease of Use for 2D and 3D Information Visualizations of Web Content. In International Journal of Human-Computer Studies: Special Issue on Empirical Evaluations of Information Visualizations, 53(5), 695-714, 2000.

[Rob00a] Robertson, G. et al. The Task Gallery: A 3D Windows Manager. Proceedings of CHI '2000, Human Factors in Computing Systems, pp. 494-501, ACM press, 2000.

[Rob98a] Robertson, G., Czerwinski, M., Larson, K., Robbins, D., Thiel, D., and Dantzich, M. Data Mountain: Using Spatial Memory for Document Management. Proceedings of UIST '98, 11th Annual Symposium on User Interface Software and Technology, pp. 153-162, 1998. 
[Rob93a] Robertson, G., Card, S., Mackinlay, J. Information visualization using 3D interactive animation. CACM, pp. 57-71, 1993.

[Rob93b] Robertson, G., Card, S. and Mackinlay, J. Nonimmersive Virtual Reality. IEEE Computer 26(2 February), pp 81-83, 1993.

[Rud98a] Ruddle, R., Payne, S., and Jones, D. Navigating large scale "desktop" virtual buildings: Effects of orientation aids and familiarity. Presence: Teleoperators and Virtual Environments, Volume 7, pp 179-192, 1998.

[Rud99a] Ruddle, R., Payne, S., and Jones, D. Navigating large scale virtual environments: what differences occur between helmet-mounted and desk top displays? Presence: Teleoperators and Virtual Environments Volume 8, Number 2, pp 157-168, 1999.

[Sat95a] Satalich, G. Navigation and Wayfinding in Virtual Reality: Finding proper tools and cues to enhance navigations awareness. Tese de Mestrado pela Universidade de Washington, 1995.

[Smith1993a] Smith, R. Psychology. West Publishing Company, 1993.

[Spe99a] Spence, R. A framework for navigation. International Journal of HumanComputer Studies, volume 51, p. 919. 1999.

[Ton95a] Tong, F., Marlin, S., Frost, B. Cognitive Map Formation in a 3D Visual Virtual World. Presented at the IRIS/PRECARN Workshop, 1995.

[Vin99a] Vinson, N. Design guidelines for landmarks to support navigation in virtual environments. Proceedings of CHI 99, p. 278-285. 1999.

[Wan92a] Wang, W., e Grinstein, G. Perceiving spatial relationships in computergenerated images. IEEE Computer Graphics and Applications 12(3), p. 44-58, 1992.

[Wei98a] Weisflog, Walter. Michaelis Moderno Dicionário da Lingua Portuguesa. Editora Melhoramentos, 1998.

[Wic96a] Wickens, C., Franck, G. Evaluating Stereo and Motion Cues for Visualizing Information Nets in Three Dimensions. ACM Transactions on Graphics 15, pp. 121$139,1996$.

[Wiss98a] Wiss, U. e Carr, D. A Cognitive Classification Framework for 3-Dimensional Information Visualization. Research Report LTU-TR-1998/4-SE, Lulea University of Technology. 